\title{
Modeling waves, currents and sandbars on natural beaches: The effect of surface rollers
}

\author{
F. Ribas ${ }^{\text {a,* }}$, H.E. de Swart ${ }^{\text {}}$, D. Calvete ${ }^{c}$, A. Falqués ${ }^{c}$ \\ a Department of Applied Physics, Universitat Politècnica de Catalunya, Campus del Baix Llobregat, Edifici C3, Esteve Terradas 5, 08860 Castelldefels, Spain \\ b Institute for Marine and Atmospheric research Utrecht, Utrecht University, Princetonplein 5, 3584 CC Utrecht, The Netherlands \\ c Department of Applied Physics, Universitat Politècnica de Catalunya, Campus Nord, Edifici B5, Jordi Girona 1-3, 08034 Barcelona, Spain
}

\section{A R T I C L E I N F O}

Available online 1 March 2011

\section{Keywords:}

Coastal zone

Nearshore bars

Longshore currents

Waves on beaches

Rollers

Longshore sediment transport

\begin{abstract}
A B S T R A C T
A morphodynamic model has been extended to gain more fundamental knowledge about the formation of nearshore sand bars. The model describes feedbacks between waves, rollers, depth-averaged currents and bed evolution, so that self-organized processes can develop. Offshore wave, wind and tide conditions and the bathymetry measured at Egmond site (the Netherlands) are firstly applied to compute the longshore current and wave height profiles. A comparison of the results with field data of that beach reveals that including the roller dynamics and the forcing by wind shear stresses and tide-induced sea level slopes is essential to accurately simulate the longshore current. Several model parameters are calibrated to minimize the rootmean-square errors. Subsequently, the wave and bathymetric conditions measured at Noordwijk site (the Netherlands) are used to compare modeled crescentic bars and up-current oriented finger bars with the nearshore sandbars observed at this site. Positive feedback leading to realistic formation of up-current bars only occurs if a novel term, i.e., the resuspension of sediment due to the turbulence created by the rollers, is included in the model. The modeled wavelength, crest orientation and growth rate agree with those of the observed up-current bars but the model overestimates the migration rate. The wavelength and migration rates of crescentic bars in case of oblique wave incidence are more accurately simulated if the reference longshore current is modeled including the roller dynamics.
\end{abstract}

(c) 2011 Elsevier B.V. All rights reserved.

\section{Introduction}

The nearshore region of coastal zones is a highly complex environment where many physical processes compete at a wide range of length and time scales. Nearshore sandbars are elongated accumulations of sand in the surf zone, with length scales from tens to hundreds of meters and evolving at time scales from hours to days. Their development is linked to the horizontal dynamics of the mean currents, free surface elevation and wave transformation. One to three shore-parallel sandbars, the most common example of nearshore sandbars, are often found at different cross-shore positions of open dissipative beaches (Short, 1999). Under intermediate wave conditions, these bars can develop alongshore inhomogeneities that consist of shallower and deeper areas alternating along the bar. The resulting pattern, called crescentic bar pattern or rip channel system, has an alongshore undulating shape in plan view with wavelengths of

\footnotetext{
* Corresponding author.

E-mail addresses: francesca.ribas@upc.edu (F. Ribas), h.e.deswart@uu.nl (H.E. de Swart), daniel.calvete@upc.edu (D. Calvete), albert.falques@upc.edu (A. Falqués).
}

hundreds of meters (van Enckevort et al., 2004). Another example of alongshore rhythmic topography at the beach are patches of several transverse finger sandbars, which are attached to the low-tide shoreline and extend up to $50 \mathrm{~m}$ into the inner surf zone (i.e., the region where water depth is smaller than $1 \mathrm{~m}$, see an example of this pattern in Ribas and Kroon (2007)). They can have an oblique orientation with respect to the shore-normal and they are often spaced with a remarkably constant alongshore periodicity of tens of meters. The transverse finger bars have different characteristics and origin from the transverse bars in the traditional beach states (like those of the 'Transverse bar and rip state' of (Wright and Short, 1984)). The latter are much wider and less elongated and they develop when the horns of a preexisting crescentic bar weld to the beach.

Crescentic bars have been observed on many beaches (33 references are listed in Table 1 of van Enckevort et al. (2004)) but extensive quantitative descriptions of their characteristics and dynamics have only been reported recently, owing to the use of video cameras that monitor the beach permanently. For instance, van Enckevort et al. (2004) used hourly time-averaged video images to study in detail the crescentic bars of 4 beaches, including Duck (USA) and Noordwijk (the Netherlands). Crescentic bars were wiped 
out during high energy periods and reformed during post storm intermediate wave conditions (that lasted 1-3 days). Their alongshore spacings ranged from 150 to $1500 \mathrm{~m}$ and the bars migrated along the coast with velocities up to $2.5 \mathrm{~m} / \mathrm{h}$.

Konicki and Holman (2000) and Ribas and Kroon (2007) also used video images to describe the characteristics of transverse finger bars at Duck and at Noordwijk (Fig. 1), respectively. The detected bars were most often located inside the trough of the innermost shoreparallel bar, attached to the low-tide shoreline, and the alongshore spacings between bars ranged from 20 to $200 \mathrm{~m}$. Finger bar characteristics were described in more detail at Noordwijk site: bar crests deviated from the shore-normal by some $30^{\circ}$ in the up-flow direction ('up-current orientation') and bar patches migrated as a whole in the direction of the longshore current at rates up to $1 \mathrm{~m} / \mathrm{h}$. Incident waves detected in Noordwijk during bar presence had an averaged root mean square wave height of $0.8 \mathrm{~m}$ and showed large angles of incidence with respect to the shore-normal $\left(\theta^{\text {off }} \approx 50^{\circ}\right.$, measured at $18 \mathrm{~m}$ depth).

These two types of alongshore rhythmic topography are interesting from a scientific point of view because they are visible manifestations of physical mechanisms that may dominate the morpho- and hydrodynamics of the surf zone of open dissipative beaches at these length scales. A possible explanation for their formation is based on the concept of morphodynamic self-organization (see, e.g., Dodd et al. (2003)). Topographic perturbations superimposed on an alongshore uniform beach induce hydrodynamic perturbations, which can lead to convergence of sand transport over the bars, hence producing a positive feedback. Linear stability analysis is a useful tool to investigate the possible feedbacks, yielding information about the shape, the growth rate and the migration speed of the initially emerging sandbars. It also allows for a systematic exploration of the sensitivity of bar characteristics to the beach conditions and to the model formulation of different physical processes. Nonlinear models are used to describe the finite-amplitude features and verify the results of the linear stability analysis.

The formation of realistic crescentic bars has been reproduced by many linear (Deigaard et al., 1999; Falqués et al., 2000; Calvete et al., 2005) and nonlinear (Caballeria et al., 2002; Damgaard et al., 2002; Reniers et al., 2004; Garnier et al., 2008) morphodynamic models. A self-organization physical mechanism called 'bed-surf coupling', first described by Falqués et al. (2000), explains the formation of crescentic bars in the majority of these models. This mechanism is strongest for shore-normal waves, but it can also model crescentic bar formation for oblique wave incidence. In the latter case, however, the wavelengths and the migration rates are overpredicted by the models (Calvete et al., 2005).

Less attention has been paid to explaining the formation of transverse finger bars, probably due to their less frequent presence in nature, and the physical mechanism behind their formation is still not clear (Ribas et al., 2003; Klein and Schuttelaars, 2005; Garnier et al., 2006; van Leeuwen et al., 2006). In these existing highly idealized studies, the simulated shapes (orientation of oblique bars with respect to the longshore current) and the time scales for growth and migration strongly depended on the specific description of wave propagation and sediment transport. Another serious limitation of our present knowledge of transverse finger bars is the lack of quantitative comparison between model results and field data, partly due to the lack of systematic quantitative descriptions of transverse finger bars. The study of Ribas and Kroon (2007) used the field observations at Noordwijk to test the physical mechanisms proposed for transverse bar formation. Considering that Noordwijk bars were up-current oriented and that they emerged during periods of clearly oblique wave incidence, only the 'bed-flow coupling', described by Ribas et al. (2003), remained as a viable explanation for their formation. The crucial factor in this mechanism is the cross-shore distribution of the depth-averaged concentration of suspended sediment, $C_{\mathrm{da}}$. As explained in Ribas et al. (2003), the 'bed-flow coupling' is dominant in case of large angles of wave incidence, the presence of strong longshore currents being essential. The growing bars locally modify the longshore current, which veers towards the direction of maximum topographic gradient due to mass conservation. Hence offshore deflection takes place over up-current oriented bars so that positive feedback only occurs if $C_{\mathrm{da}}$ decreases seaward across the inner surf zone, because this enhances the convergence of sediment flux in the offshore-directed flows. Both the linear model by Ribas et al. (2003) and the nonlinear model by Garnier et al. (2006) reproduced the formation of up-current oriented bars with realistic length and time scales, but they were highly idealized. In particular, an arbitrary spatially uniform depth-integrated sediment concentration was assumed so that $C_{\mathrm{da}}$ decreased seaward and up-current bars would grow. When more standard formulations for the nearshore sediment transport were used in those studies, $C_{\mathrm{da}}$ increased seaward in the inner surf zone and up-current bars were not reproduced. There is the need to find a physically founded explanation for the decreasing cross-shore profile of $C_{\mathrm{da}}$. Surface rollers can play a crucial role in this respect because they create turbulent bores that can lead to significant sediment resuspension in the inner surf zone. This may give a cross-shore distribution of $C_{\mathrm{da}}$ that could explain the formation of up-current bars.

In order to gain a deeper understanding on the formation of nearshore sandbars it is essential to test model results (and thereby the underlying physical mechanisms) against field observations. This holds in particular for transverse finger bars, as their formation mechanism is not well understood. A necessary previous step in this context is to model cross-shore profiles of the wave height and longshore current that resemble those observed in the field. Many studies have performed a calibration of wave transformation models. Usually a single parameter is adjusted, the saturation ratio of rms wave height over water depth, $\gamma_{b}$, which is considered to be a free model parameter (Lippmann et al., 1996; Apotsos et al., 2007). In order to model longshore current profiles accurately, especially on beaches comprising shore-parallel bars, the inclusion of the surface rollers as well as the forcing by wind and tidal waves was proved to be essential (Reniers et al., 1997; Feddersen et al., 1998; Ruessink et al., 2001). Ruessink et al. (2001) used data collected near Egmond aan Zee

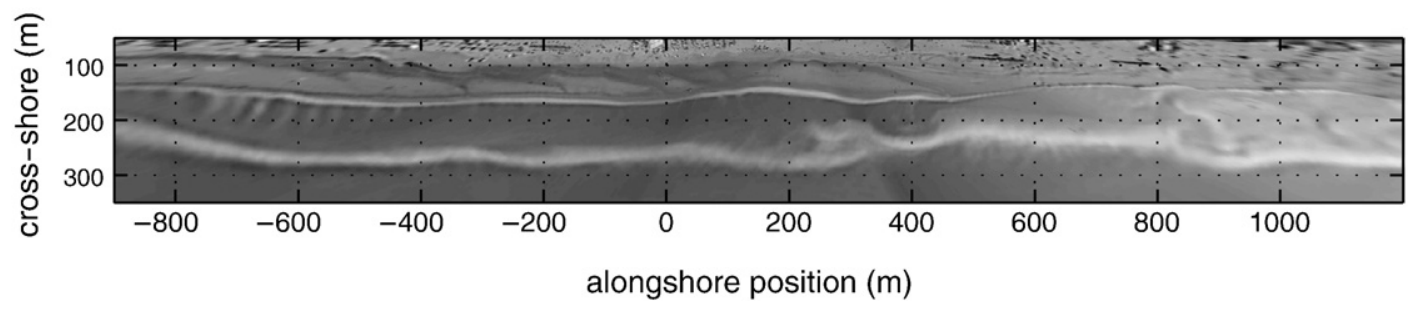

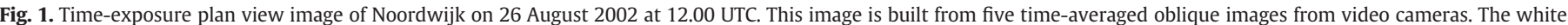

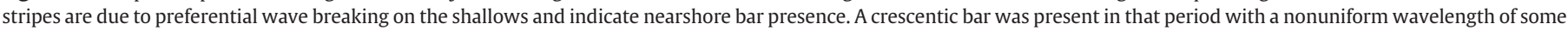

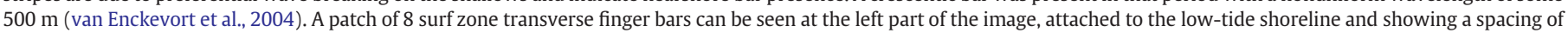

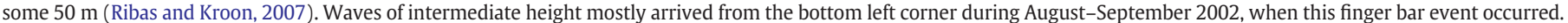


(the Netherlands, Coast3D experiment) and near Duck (USA, Duck94 experiment) in order to validate the results of a $1 \mathrm{D}$ model. They adjusted the value of several model parameters, such as the apparent bed roughness, $k_{a}$, so that the root mean square errors between modeled and measured currents were minimized.

The objectives of the present study are twofold. Firstly, we aim at modeling wave height and longshore current profiles that agree well with those observed at natural beaches. The second objective is testing the effect of surface rollers into the formation of nearshore sand bars due to self-organization. To achieve these objectives, we have extended an existing morphodynamic model based on linear stability analysis to include the roller dynamics (and also the wind and tidal forcing, see Section 2 for the model formulation). The model is first applied to the conditions measured at Egmond beach in autumn 1998, in order to compare the modeled longshore current and wave height profiles with the Coast3D field data (Section 3). Also, model parameters like $\gamma_{b}$ and $k_{a}$ are calibrated to minimize the root mean square errors. The next step, described in Section 4, is to apply the model to the conditions measured at Noordwijk beach during August and September 2002, when a crescentic bar and a patch of upcurrent oriented finger bars were observed. Modeled bar characteristics are then analyzed and compared with the observations. The comparison of the wave height and current profiles is not performed at Noordwijk beach because no measurements of this kind are available. Finally, the conclusions are given in Section 5.

\section{Model formulation}

The model employed in the present study is an extension of the model called MORFO60 (Calvete et al., 2005), which describes the feedback between waves, depth-averaged currents, free surface elevation and bed evolution. An extended version of the equations for the roller dynamics has been incorporated, together with the possibility of accounting for wind shear stresses and tide-induced sea surface level slopes. A novel term has also been included in the sediment transport formulation, which accounts for the resuspension of sediment due to the turbulence created by the rollers.

The $y$ ( or $x_{2}$ ) axis is chosen to coincide with the rectilinear shoreline, the $x$ (or $x_{1}$ ) axis points in the seaward direction and the $z$ axis points upwards. At a Dutch beach like the one in Fig. 1, the $y$ axis points towards the south. All the equations and quantities are phaseaveraged, hence the described time scales are longer than $1 \mathrm{~min}$.

\subsection{Hydrodynamics}

Waves are assumed to have a narrow spectrum in frequency and angle. Their heights are supposed to be random and follow the Rayleigh distribution, characterized by the root-mean-square (rms) wave height, $H_{\mathrm{rms}}$. Here, $H_{\mathrm{rms}}=\sqrt{8 E /(\rho g)}$, with $E$ being the wave energy density, $\rho$, the water density, and $g$, gravity. When waves approach the coast, their evolution is described using linear wave theory, which yields expressions for the wave properties such as the root mean square wave orbital velocity amplitude, $u_{\text {rms }}$, the phase speed, $c$, and the magnitude of the group velocity, $c_{g}$. The intrinsic wave frequency is computed from the dispersion relation. When introducing the Doppler shift to relate the intrinsic frequency to the absolute frequency, $\omega_{a}$, the following relation is obtained,

$\omega_{a}=\sqrt{g|\vec{K}| \tanh (|\vec{K}| D)}+v_{j} K_{j}, \quad j=1,2$

Here, $K_{j}$ are the two components of the wave vector $\vec{K}, v_{j}$ are the components of the depth-averaged fluid velocity $\vec{v}$, and $D=z_{s}-z_{b}$ is the water depth, where $z_{s}$ is the mean free surface elevation and $z_{b}$ is the sea bottom level. Steady conditions are assumed, $\omega_{a}=$ constant. Due to the irrotationality of the wavenumber,

$\frac{\partial K_{j}}{\partial x_{k}}-\frac{\partial K_{k}}{\partial x_{j}}=0, \quad j, k=1,2$,

Eq. (1) can be rewritten in terms of the wave phase $\Phi$, from which the two components of the wave vector can be computed, $K_{i}=\partial \Phi / \partial x_{i}$. The wave incidence angle with respect to shore-normal, $\theta$, is computed from the components of the wave vector (positive angles refer to waves traveling in the negative $x$ and positive $y$ directions). Eqs. (1) and (2) describe the refraction of the waves due to both topography and currents. More complex processes in wave propagation, like wave diffraction, are not accounted for.

The wave energy balance includes wave-current interactions and reads,

$$
\begin{aligned}
\frac{\partial E}{\partial t} & +\frac{\partial}{\partial x_{j}}\left(\left(v_{j}+c_{g j}\right) E\right)+ \\
& +S_{j k}^{w} \frac{\partial v_{k}}{\partial x_{j}}=-\mathcal{D}^{w}, \quad j, k=1,2
\end{aligned}
$$

Here, $c_{g j}$ are the components of the group velocity and $S_{i j}^{w}$ are the wave radiation stresses, which are computed using linear wave theory,

$S_{j k}^{w}=E\left(\frac{c_{g}}{c} \frac{K_{j} K_{k}}{|\vec{K}|^{2}}+\left(\frac{c_{g}}{c}-\frac{1}{2}\right) \delta_{j k}\right), \quad j, k=1,2$,

where $\delta_{j k}$ is the Kronecker delta. The energy dissipation rate due to wave breaking, $\mathcal{D}^{w}$, is the most critical parameterization in Eq. (3). A variety of formulations are available nowadays, which have been tested extensively against field data. We use the standard formulation by Thornton and Guza (1983),

$\mathcal{D}^{w}=\frac{3 B^{3} \rho g \omega_{a} H_{\mathrm{rms}}^{5}}{32 \sqrt{\pi} \gamma_{b}^{2} D^{3}}\left(1-\left(1+\left(\frac{H_{\mathrm{rms}}}{\gamma_{b} D}\right)^{2}\right)^{-2.5}\right)$,

with $B$ describing the fraction of broken waves and $\gamma_{b}$ being the saturation ratio of $H_{\mathrm{rms}} / D$. This formulation proved to simulate accurate rms wave height when compared against field data at USA beaches (Lippmann et al., 1996; Apotsos et al., 2007). We assume that $B=1$, so that the entire front of the wave is conceived to be covered with foam, consistent with the derivation of the roller equations (Lippmann et al., 1996). The parameter $\gamma_{b}$ is assumed to be cross-shore uniform and we use a range of realistic values (see Table 1 and (Thornton and Guza, 1986)).

The energy dissipated by wave breaking feeds the surface rollers, i.e. the aerated mass of water located on the shoreward face of the breaking waves. The roller energy balance is an extension of the one

Table 1

Default parameter setting (where the default values for $\gamma_{b}$ and $k_{a}$ are those best reproducing Egmond observations) and range of variation.

\begin{tabular}{llcl}
\hline & Meaning & Default & Range \\
\hline$\gamma_{b}$ & Saturation ratio & 0.475 & $0.35-0.6$ \\
$\beta_{\text {rol }}$ & Slope of wave/roller front & 0.05 & $0.03-0.1$ \\
$k_{a}$ & Apparent bed roughness & $0.035 \mathrm{~m}$ & $0.005-0.1 \mathrm{~m}$ \\
$M$ & Turbulence parameter & 1 & $0.1-10$ \\
$n_{\text {bor }}$ & Bore stirring parameter & 50 & 0 and 50 \\
$H_{\mathrm{rms}}^{\text {off }}$ & Offshore rms wave height & $1 \mathrm{~m}$ & $0.25-2 \mathrm{~m}$ \\
$T_{p}$ & Peak wave period & $6 \mathrm{~s}$ & $4-12 \mathrm{~s}$ \\
$\left|\theta^{\text {off }}\right|$ & Offshore wave incidence angle & $50^{\circ}$ & $0-70^{\circ}$ \\
$\left|\tau_{w}\right| / \rho$ & Wind shear stress / $\rho$ & 0 & $0-10^{-3} \mathrm{~m}^{2} / \mathrm{s}^{2}$ \\
$|d \zeta / d y|$ & Tide-induced sea level slope & 0 & $0-2 \cdot 10^{-5}$ \\
\hline
\end{tabular}


proposed by Reniers et al. (2004), which we have adapted to account for wave-current interactions,

$$
\begin{aligned}
\frac{\partial\left(2 E^{r}\right)}{\partial t} & +\frac{\partial}{\partial x_{j}}\left(2\left(v_{j}+c_{j}\right) E^{r}\right) \\
& +S_{j k}^{r} \frac{\partial v_{k}}{\partial x_{j}}=-\mathcal{D}^{r}+\mathcal{D}^{w}, \quad j, k=1,2 .
\end{aligned}
$$

In this equation, $E^{r}$ is the energy density of the rollers, $c_{j}$ are the components of the phase speed along the $x_{j}$ axis and $S_{i j}^{r}$ are the radiation stresses due to roller propagation, which are computed following (Svendsen, 1984),

$S_{j k}^{r}=2 E^{r} \frac{K_{i} K_{j}}{|\vec{K}|^{2}}, \quad j, k=1,2$.

Finally, the roller energy dissipation rate, $D^{r}$, in Eq. (6) is modeled following (Ruessink et al., 2001),

$\mathcal{D}^{r}=\frac{2 g E^{r} \sin \left(\beta_{\text {rol }}\right)}{c}$

where $\beta_{\text {rol }}$ is the angle of the wave/roller interface, usually assumed to be 0.1 or less (Ruessink et al., 2001). Wave conditions are prescribed offshore ( $H_{r m s}^{\text {off }}, \theta^{\text {off }}$ and $\omega_{a}=2 \pi / T_{p}$, where $T_{p}$ is the peak period). The offshore boundary is located at the water depth of the buoy in the corresponding site (16 $\mathrm{m}$ depth at Egmond site and $18 \mathrm{~m}$ depth at Noordwijk site).

The currents are governed by the depth-averaged mass and momentum balance equations,

$$
\begin{aligned}
\frac{\partial D}{\partial t}+\frac{\partial}{\partial x_{j}}\left(D v_{j}\right) & =0, \quad j=1,2, \\
\frac{\partial v_{i}}{\partial t}+v_{j} \frac{\partial v_{i}}{\partial x_{j}}= & -g \frac{\partial z_{s}}{\partial x_{i}}-\frac{1}{\rho D} \frac{\partial}{\partial x_{j}}\left(S_{i j}^{w}+S_{i j}^{r}-S_{i j}^{t}\right) \\
& -\frac{\tau_{b i}}{\rho D}+\frac{\tau_{w i}}{\rho D}, \quad i, j=1,2 .
\end{aligned}
$$

Note that Eq. (10) includes the radiation stresses due to both wave and roller propagation. Furthermore, $\tau_{b i}$ are the bed shear stresses, $\tau_{w i}$ are the wind shear stresses, and $S_{i j}^{t}$ are the turbulent Reynolds stresses. The bed shear stresses are parameterized following the generalized equation developed by Feddersen et al. (2000), which we have extended to model the effect of a 2-dimensional flow,

$\tau_{b i}=\rho c_{D} \frac{u_{\mathrm{rms}}}{\sqrt{2}} v_{i}\left(1.16^{2}+2 \frac{|\vec{v}|^{2}}{u_{\mathrm{rms}}^{2}}\right)^{1 / 2}, \quad i=1,2$,

with $c_{D}$ being a bottom drag coefficient. According to Feddersen et al. (2000) and Ruessink et al. (2001), this empirical parameterization adequately represents the shear stresses for the random wave field at both Duck and Egmond beaches, respectively. The drag coefficient $c_{D}$ is the dimensionless friction coefficient due to current and waves and it is supposed to vary with depth following the Manning-Strickler law (Soulsby, 1997),

$c_{D}=0.015\left(\frac{k_{a}}{D}\right)^{1 / 3}$.

Here, the parameter $k_{a}$ is the apparent bed roughness, assumed to be constant in time and space, and a range of realistic values are used (see Table 1 and Ruessink et al. (2001)). Field observations have revealed that larger $c_{D}$ values occur inside the surf zone due to breaking-wave generated turbulence (Feddersen et al., 1998; Feddersen et al., 2000). The wind shear stresses in Eq. (10) are computed with a standard quadratic law,

$\tau_{w i}=\rho_{a} c_{d w}\left|\vec{u}_{w}\right| u_{w i}, \quad i=1,2$,

where $\rho_{a}$ is the air density, $u_{w i}$ are the two components of the wind velocity $\vec{u}_{w}$ and $c_{d w}$ is a constant drag coefficient, for which a standard value of 0.002 is used. The turbulent Reynolds stresses, $S_{i j}^{t}$ in Eq. (10), are modeled with the standard eddy viscosity approach,

$S_{i j}^{t}=\rho v_{t} D\left(\frac{\partial v_{i}}{\partial x_{j}}+\frac{\partial v_{j}}{\partial x_{i}}\right), \quad i, j=1,2$.

The lateral turbulent mixing coefficient $\nu_{t}$ is directly linked to the roller energy dissipation (the main source of turbulence), $\nu_{t}=M\left(D^{r} / \rho\right)^{1 / 3}$, where $M$ is a turbulence parameter of order 1 .

\subsection{Bed evolution}

Conservation of sediment mass yields the bottom evolution equation

$\frac{\partial z_{b}}{\partial t}+\frac{1}{1-p} \frac{\partial q_{j}}{\partial x_{j}}=0, \quad j=1,2$

with $p=0.4$ being the porosity of the bed and $q_{i}$ the two components of the wave- and depth-averaged volumetric sediment transport $\left(\mathrm{m}^{2} / \mathrm{s}\right)$. A widely accepted formulation for $q_{i}$ in the nearshore is that of Soulsby and van Rijn (Soulsby, 1997). Their original expression has been extended to model the effect of a 2-dimensional flow and to modify the preferred downslope transport of the sand,

$q_{i}=C\left(v_{i}-\Gamma \frac{\partial h}{\partial x_{i}}\right), \quad i=1,2$.

In this expression $C$ can be interpreted as the depth-integrated volumetric sediment concentration due to the stirring by waves and currents. The depth-averaged sediment concentration mentioned in Section 1 is $C_{d a}=C / D$. The second term inside the parenthesis of Eq. (16), where $\Gamma$ is called bed slope coefficient, accounts for the tendency of the system to smooth out the sea bed perturbations, $h$, if the latter do not cause positive feedback into the flow.

The depth-integrated concentration $C$ in Eq. (16) reads

$\begin{array}{ll}C=A_{s}\left(u_{\text {stir }}-u_{\text {crit }}\right)^{2.4}, & \text { if } u_{\text {stir }}>u_{\text {crit }}, \\ C=0 & \text { otherwise. }\end{array}$

Here, the parameter $A_{s}$ accounts for the sediment properties, $u_{\text {crit }}$ is the threshold flow intensity for sediment transport and $u_{\text {stir }}$ is a representative stirring velocity responsible for sediment resuspension. The full expressions for $u_{\text {crit }}$ and $A_{s}$ are given in Soulsby (1997). Using the default parameter setting (Table 1 ) and the grain size measured at the Dutch coast, $d_{50}=0.2 \mathrm{~mm}, u_{\text {crit }}$ ranges from $0.2 \mathrm{~m} / \mathrm{s}$ near the shoreline to $0.4 \mathrm{~m} / \mathrm{s}$ far offshore and $A_{s}$ is about $10^{-3} \mathrm{~s}^{2.4}$ / $\mathrm{m}^{1.4}$. We have extended Soulsby and van Rijn expression for $u_{\text {stir }}$ in Eq. (17) to include an extra contribution due to the stirring of sediment created by the roller-induced turbulence,

$u_{\text {stir }}=\sqrt{|\vec{v}|^{2}+0.018 c_{D}^{-1} u_{\mathrm{rms}}^{2}+n_{\text {bor }} u_{\text {bor }}^{2}}$,

where $u_{\text {bor }}$ is a representative velocity of the turbulent bores created after roller energy is dissipated and $n_{\text {bor }}$ is a constant parameter. In the original Soulsby and van Rijn formulation, $u_{\text {stir }}$ was assumed to be a result of the shear stresses produced in the bottom boundary layer of the wave orbital velocity and the depth-averaged currents (first two terms inside the square root in Eq. (18)). The Soulsby and van Rijn formulation was shown to be accurate in the shoaling domain, at 
water depths of the order of $5 \mathrm{~m}$ (Soulsby, 1997). However, in the inner surf zone (depths $<1 \mathrm{~m}$ ), where $u_{\mathrm{rms}}$ and the longshore current decay, other processes like the turbulence created by roller propagation also produce significant sediment resuspension (Voulgaris and Collins, 2000; Butt et al., 2004). In the present study, the third term inside the square root in Eq. (17) has been added to allow inclusion of this other possible process. We follow Roelvink and Stive (1989) and Reniers et al. (2004), who assumed that this extra $u_{\text {bor }}$ was proportional to the dissipation of roller energy, i.e.,

$u_{\mathrm{bor}}^{2}=\left(\frac{\mathcal{D}^{r}}{\rho}\right)^{\frac{2}{3}}\left(e^{\left(D / H_{\mathrm{rms}}\right)}-1\right)^{-1}$

where the exponential function accounts for the decrease of the turbulent velocity from the surface to the bed. By varying the parameter $n_{\text {bor }}$ in Eq. (18), we can change the strength of the sediment resuspension due to roller-induced turbulence. Values of $n_{\text {bor }}$ of about 50 give reasonable values of $C$ of the order of $10^{-3} \mathrm{~m}$ in the inner surf zone (Roelvink and Stive, 1989). The original Soulsby and van Rijn expression for $C$ is obtained with $n_{\text {bor }}=0$. The Manning-Strickler law (Eq. (12)) is again assumed for the drag coefficient $c_{D}$ in Eq. (18).

The bed slope coefficient $\Gamma$ in Eq. (16) is also assumed to depend on the stirring velocity $u_{\text {stir }}$,

$$
\begin{array}{ll}
\Gamma=\gamma\left(u_{\text {stir }}-u_{\text {crit }}\right) \quad, \text { if } u_{\text {stir }}>u_{\text {crit }} \\
\Gamma=0
\end{array}
$$

where $\gamma$ is the bed slope parameter. The default value $\gamma=0.6$ yields bed slope coefficients similar in magnitude as those of the original Soulsby and van Rijn formulation (Soulsby, 1997).

\subsection{Methodology}

Eqs. (1), (2), (3), (6), (9), (10) and (15), which govern our morphodynamic system, together with the parameterizations used, define a closed dynamical system for the variables $\Phi, E, E_{r}, z_{s}, \vec{v}$ and $z_{b}$. The stability analysis approach to the formation of bars by selforganization starts by defining a steady and alongshore uniform reference state (i.e., without alongshore rhythmic topography). In this study, we used reference profiles, $z_{b}^{o}(x)$, measured in the Dutch coast, which showed two well-developed shore-parallel bars (see the lower panel of Fig. 2). The superscript ${ }^{\circ}$ denotes the basic state variables. As a result of the convergence of wave radiation stresses due to breaking, the modeled basic state is characterized by the presence of a longshore current, $\vec{v}^{0}=\left(0, V^{o}(x)\right)$, and an elevation of the free surface level (i.e., the setup), $z_{s}^{o}(x)$. The total free surface level in the basic state, $z_{s, t o t}^{o}(x, y)=z_{s}^{o}(x)+\zeta(y)$, has a cross-shore variable component $z_{s}^{o}(x)$, and an alongshore variable component $\zeta(y)$ (due to the presence of a tidal wave). It is assumed that $\zeta<<D^{o}$, where $D^{o}(x)=$ $z_{s}^{o}(x)-z_{b}^{o}(x)$, which means that the rigid lid approximation is imposed. As a consequence, only the alongshore gradient of this quantity, $d \zeta / d y$, appears in the equations, acting as a pressure gradient in the alongshore component of Eq. (10). Finally, $d \zeta / d y$ is assumed to be spatially uniform and invariant in time, i.e, the surface slope is kept constant while computing waves and currents $(d \zeta / d y$ is set equal to 0 when solving the bed evolution equation).

Two of the modeled quantities of this reference state, the rms wave height, $H_{\mathrm{rms}}^{o}$, and the longshore current, $V^{\circ}$, are first analyzed and compared with field data obtained at Egmond site. The default values of two model parameters, $\gamma_{b}$ and $k_{a}$, are then chosen such that the rms error of $H_{\mathrm{rms}}^{o}(x)$ and $V^{o}(x)$ (respectively) are minimum. The default values of the other model parameters are chosen either because they are standard widely used values (i.e., $\beta_{\text {rol }}$ and $M$ ) or because they are observed mean values in the Dutch coast (i.e., offshore wave, wind and tide conditions).

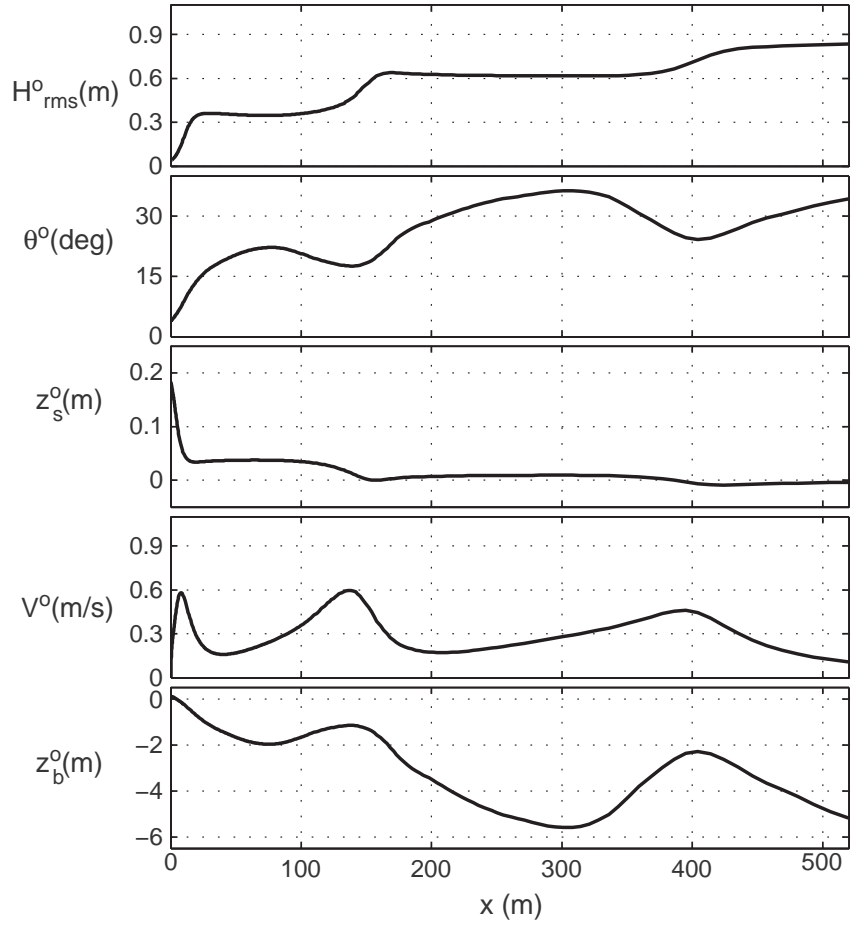

Fig. 2. Result for the reference state at Egmond site using the default parameter setting. The panels show, from top to bottom, the cross-shore profiles of the rms wave height, the angle of wave incidence with respect to shore-normal, the sea surface level, the longshore current and the bed level. The bathymetry was measured at Egmond site, the Netherlands, on 18 October 1998 for a tidal level of $-0.33 \mathrm{~m}$.

Once the basic state has been computed and compared with field observations, the linear stability analysis can be applied in a standard way (Dodd et al., 2003). A small perturbation, assumed to be periodic in time and in the alongshore coordinate, is added to this state. For instance, for the bed level this reads

$z_{b}(x, y, t)=z_{b}^{o}(x)+\mathfrak{R} e\left(e^{\omega t+i k y} h(x)\right)$

where $h$ stands for the cross-shore distribution of the perturbations of $z_{b}, \kappa$ is the alongshore wavenumber of these perturbations and $\omega$ is a complex growth rate. Expressions similar to Eq. (21) are used for the other six variables, where $\phi(x), e(x), e^{r}(x), \eta(x), u(x)$ and $v(x)$ correspond to the cross-shore structure of the perturbations in $\Phi, E, E^{r}$, $z_{s}, v_{1}$ and $v_{2}$, respectively. By inserting all the expressions like Eq. (21) in the governing equations and linearizing with respect to the perturbations, we arrive at an eigenproblem. For each $\kappa$, different complex eigenvalues $\omega$ exist, which characterize the different growing modes, and the complex eigenfunctions are $\left(\phi(x), e(x), e^{r}(x), \eta(x)\right.$, $u(x), v(x), h(x))$. The $e$-folding growth rate of the emerging bars is given by $\Omega=\mathfrak{R} e(\omega)$, so that $\Omega>0$ implies growth. In case of an unstable basic state, solutions with $\Omega>0$ are found and the growth rate curves show these positive $\Omega$ for different values of $\kappa$. Starting from arbitrary initial conditions, the dynamics after some time is assumed to be dominated by the mode with largest growth rate, $\Omega_{M}$, and the corresponding alongshore wavenumber $\kappa_{M}$. This fastest growing solution is the one that can be thereby compared with the observed nearshore bars. Its e-folding growth time is given by $\tau_{M}=\Omega_{M}^{-1}$ and its migration speed by $c_{M}=-\Im m\left(\omega_{M}\right) / \kappa_{M}$. The alongshore wavelength of the corresponding bar patch is $\lambda_{M}=2 \pi / \kappa_{M}$ and the shape of the bar pattern is given by $\mathfrak{R} e\left(e^{i \kappa_{M} y} h(x)\right)$. The associated patterns of the other variables are obtained in a similar way from $\phi(x), e(x), e^{r}(x), \eta(x), u(x)$ and $v(x)$ (see Dodd et al. (2003) for details). Given the uncertainties in 
the available sediment transport formulations, the function $C$ in Eq. (16) is not perturbed.

\section{Modeling the wave height and longshore current profiles}

\subsection{Model results for the reference state at Egmond site}

The model was first applied to the conditions measured at Egmond beach (the Netherlands) during an intense field campaign performed in October and November 1998. Results for the reference basic state obtained when using the bathymetry measured on 18 October 1998 and the default parameter setting are shown in Fig. 2. Note that some of the default values of the parameters (Table 1) are chosen from the calibration described in Section 3.3. The wave height decrease is mainly due to wave energy dissipation, which is concentrated in three regions, over the two shore-parallel bars and in the inner surf zone. These three regions also contain the largest changes in free surface elevation and local maxima of the longshore current. The latter results primarily from the balance between gradients in the wave radiation stresses and bed shear stresses. Wave refraction is mainly caused by changes in bed level.

The sensitivity of the reference state solution to values of some model parameters was subsequently checked (Fig. 3). Increasing the saturation ratio, $\gamma_{b}$, induced an enlargement of the rms wave height across the whole domain (panel a) and thereby an overall increase in the longshore current (not shown). The parameters $k_{a}, M$ and $\beta_{\text {rol }}$

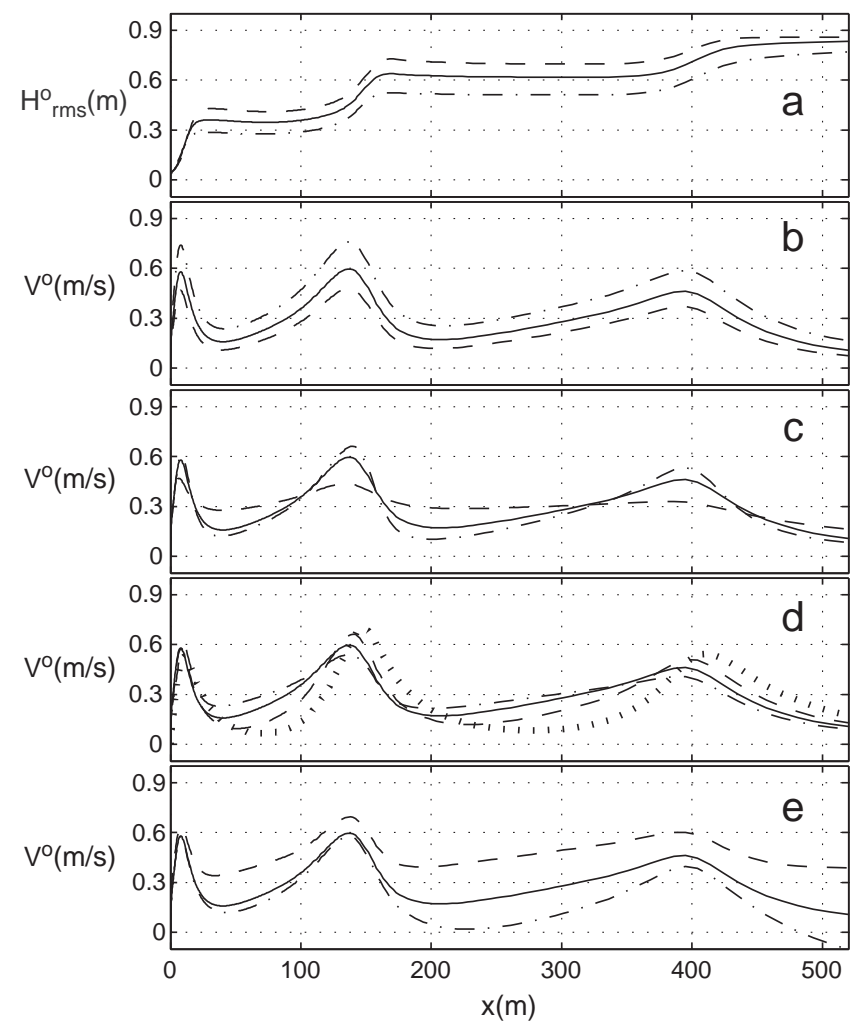

Fig. 3. Dependence of the modeled rms wave height and longshore current profiles on some model parameters and formulations. In all panels, the solid line indicates the result obtained for the default parameter setting (Table 1). The other curves correspond to the result changing one model parameter with the others held constant. Panel (a) shows the cross-shore profile of $H_{\mathrm{rms}}^{o}$ for different $\gamma_{b}$ values $\left(\gamma_{b}=0.35\right.$ in dot-dashed line and $\gamma_{b}=$ 0.60 in dashed line). Panels (b)-(e) show the cross-shore profile of $V^{o}$ for different $k_{a}$ values (b, $k_{a}=0.01$ in dot-dashed line and $k_{a}=0.1$ in dashed line), $M$ values (c, $M=0.1$ in dot-dashed line and $M=10$ in dashed line), $\beta_{\text {rol }}$ values ( $\mathrm{d}, \beta_{\text {rol }}=0.03$ in dot-dashed line, $\beta_{\text {rol }}=0.1$ in dashed line, and no roller included in dotted line), and wind and tide forcing (e, $\tau_{w y} / \rho=5 \cdot 10^{-4} \mathrm{~m}^{2} / \mathrm{s}^{2}$ in dashed line and $d \zeta / d y=5 \cdot 10^{-6} \mathrm{~m} / \mathrm{m}$ in dot-dashed line), respectively. The bed level is the same as in Fig. 2. hardly modified the $H_{\mathrm{rms}}^{o}$ profile but affected the longshore current profile. Increasing the apparent bed roughness, $k_{a}$, produced a decrease of $V^{o}$ across the whole domain without modifying its crossshore distribution. Increasing the turbulence parameter, $M$, smoothed the $V^{o}$ profile without shifting the location of current maxima. The wave-front slope, $\beta_{\text {rol }}$, was the only parameter capable of modifying the location of current maxima. Excluding the roller dynamics, narrow current peaks were located on the seaward side of the shore-parallel bars (see the dotted line in panel (d) of Fig. 3). Including the roller dynamics and decreasing the value of $\beta_{\text {rol }}$ shifted the current maxima onshore and smoothed the $V^{o}$ profile. When including a positive alongshore component of the wind shear stresses, $\tau_{w y}$, of the same sign as $\theta^{\text {off }}$ (meaning that waves travel in the direction of wind velocity, the most common situation), an overall increase of the longshore current was observed (see the dashed line in panel (e) of Fig. 3). Including a cross-shore component of the wind shear stresses, $\tau_{w x}$ hardly modified the basic state profile (not shown). Including a positive tide-induced alongshore slope of the mean sea level induced a negative forcing across the whole domain, and thereby an overall decrease of the longshore current. The effect of wind shear stresses and tide-induced sea level slope was particularly noticeable in the areas where wave breaking was smallest (i.e. in the troughs of the shore-parallel bars).

Finally, the influence of varying the offshore wave conditions, $H_{\mathrm{rms}}^{\mathrm{off}}$, $T_{p}$ and $\theta^{\text {off }}$, was checked (Fig. 4). Increasing the offshore rms wave height initially enlarged the value of $H_{\mathrm{rms}}^{o}$ and $V^{\circ}$ at the inner surf zone (see the solid line in panels (a) and (b) of Fig. 4). However, $H_{\mathrm{rms}}^{o}$ (and thereby $V^{o}$ ) in that region got saturated for $H_{\mathrm{rms}}^{\text {off }}>1 \mathrm{~m}$ because the extra wave energy for larger $H_{\mathrm{rms}}^{\text {off }}$ dissipated at the outer shoreparallel bars. The value of $H_{\mathrm{rms}}^{o}$ and $V^{o}$ at the inner bar followed the same tendency (see the dashed line in panels (a) and (b) of Fig. 4) and they reached saturation for $H_{\mathrm{rms}}^{\text {off }}>1.5 \mathrm{~m}$. Increasing the wave period, $T_{p}$, enlarged $H_{\mathrm{rms}}^{o}$ and $V^{o}$ in the two regions, the effect on the current being weaker. Increasing the offshore angle of wave incidence, $\theta^{\text {off }}$, hardly affected the wave height but it induced a strong overall increase of the longshore current.

\subsection{Field observations at Egmond site}

The Coast3D field campaign was performed during October and November 1998 near Egmond aan Zee, the Netherlands. Offshore wave conditions were measured by a directional wave buoy located in front of the beach at $16 \mathrm{~m}$ depth (Fig. 5). Wind speed and direction were measured at $10 \mathrm{~m}$ above sea level at position P1 (see the lower panels of Fig. 6). The mean sea level and the alongshore sea level slope were estimated from observations at two tidal stations separated by $30 \mathrm{~km}$ alongshore and centered around Egmond site. Pressure sensors and bidirectional current meters were deployed on a cross-shore transect, mostly over the inner bar region (see the specific locations in the lower panels of Fig. 6). Spatially dense nearshore bathymetric surveys were performed with an amphibious vehicle when wave conditions permitted such activity. The bathymetry was always slightly alongshore nonuniform, and it became clearly alongshore variable from 4 November until the end of the campaign. A more detailed description of the field data can be found in Ruessink et al. (2001).

In the present study we chose to compare the model results with the data collected on the first 9 days of observations, from 15 October until 23 October, for two main reasons. Firstly, the bathymetry was relatively alongshore uniform, in agreement with the assumption of alongshore uniformity of our 1D model. Previous studies of wave transformation and longshore current profile performed in the 1D framework established that 1D model predictions held as long as the bathymetry only showed weak alongshore inhomogeneities (Reniers et al., 1997; Feddersen et al., 1998; Ruessink et al., 2001). Secondly, the model is aimed at simulating nearshore sandbars, which occur in intermediate wave conditions like those measured during these first 

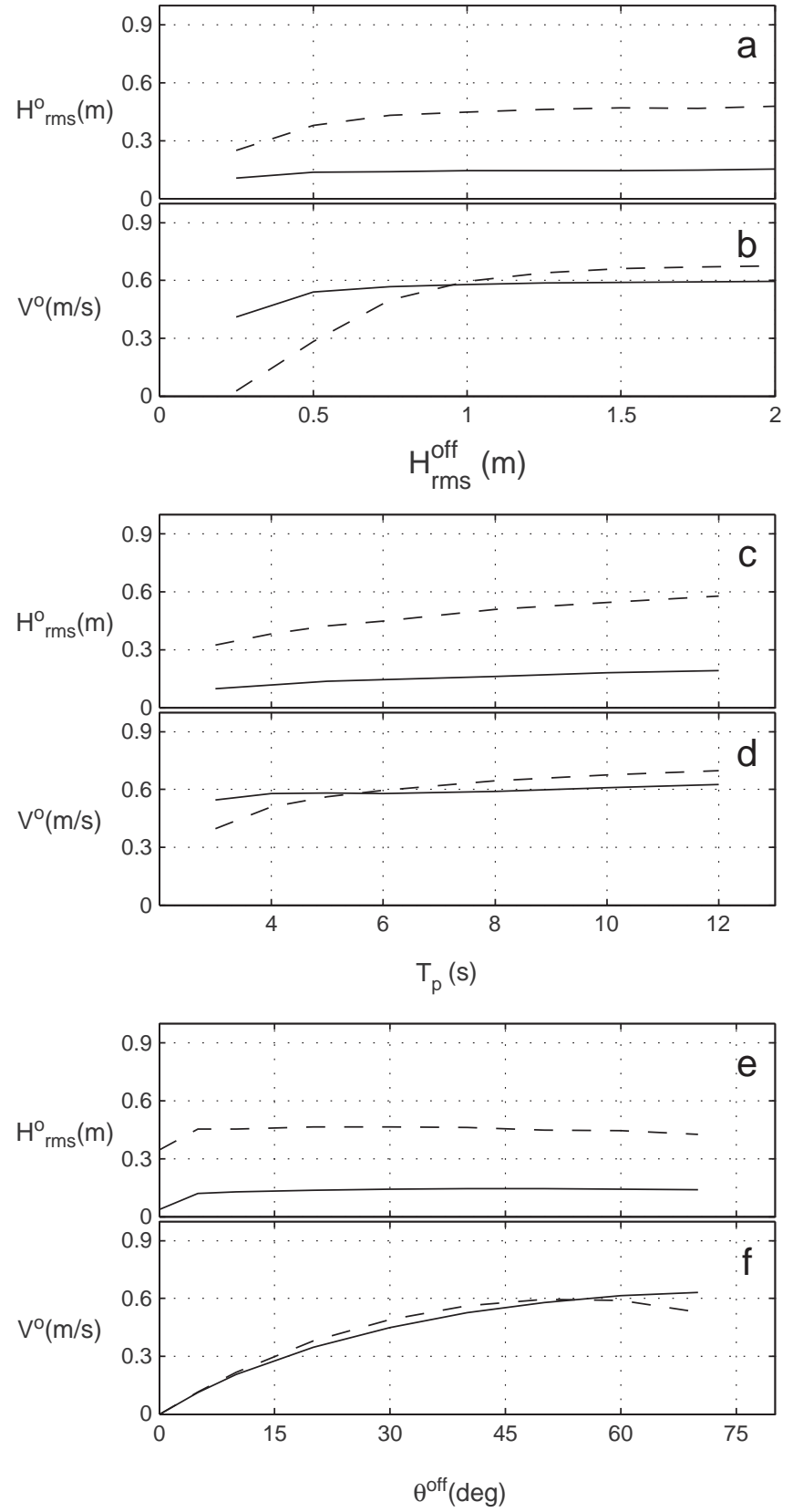

Fig. 4. Dependence of the modeled rms wave height ( $a, c$ and e) and longshore current (b, d and f) on the offshore wave conditions. Panels show the curves when varying the offshore rms wave height (a-b), the peak wave period (c-d) and the offshore wave incidence angle (e-f). In all panels, the solid line is the value obtained at the inner surf zone and the dashed line is the value obtained at the inner bar crest (specifically, at the locations of the corresponding longshore current peaks). The bed level is the same as in Fig. 2.

9 days. A big storm with $H_{\mathrm{rm}}^{\text {off }}$ up to $4 \mathrm{~m}$ started on 24 October and lasted for a few days.

During our study period, $H_{\mathrm{rms}}^{\text {off }}$ varied between 0.6 and $2.1 \mathrm{~m}, T_{p}$ between 5.2 and $8.8 \mathrm{~s}, \theta^{\text {off }}$ between $\pm 50^{\circ}$, and $\tau_{w y} / \rho$ between $-7.8 \cdot 10^{-4}$ and $2.7 \cdot 10^{-4} \mathrm{~m}^{2} / \mathrm{s}^{2}$ (Fig. 5). Tidal waves induced a $12^{\mathrm{h}}$ $25^{\mathrm{m}}$ oscillation of the mean sea level, with a range of some $1.5 \mathrm{~m}$ and alongshore slopes of the mean sea level ranging from $-10^{-5}$ and $2 \cdot 10^{-5} \mathrm{~m} / \mathrm{m}$ (see panels (d) and (e) of Fig. 5). The observed rms wave height at the six pressure sensors is shown in solid lines in Fig. 7. As can be seen, this quantity got depth limited and tidally modulated at the stations P3-P6, located over the inner bar. This phenomenon did not occur with the observed longshore current (solid lines in

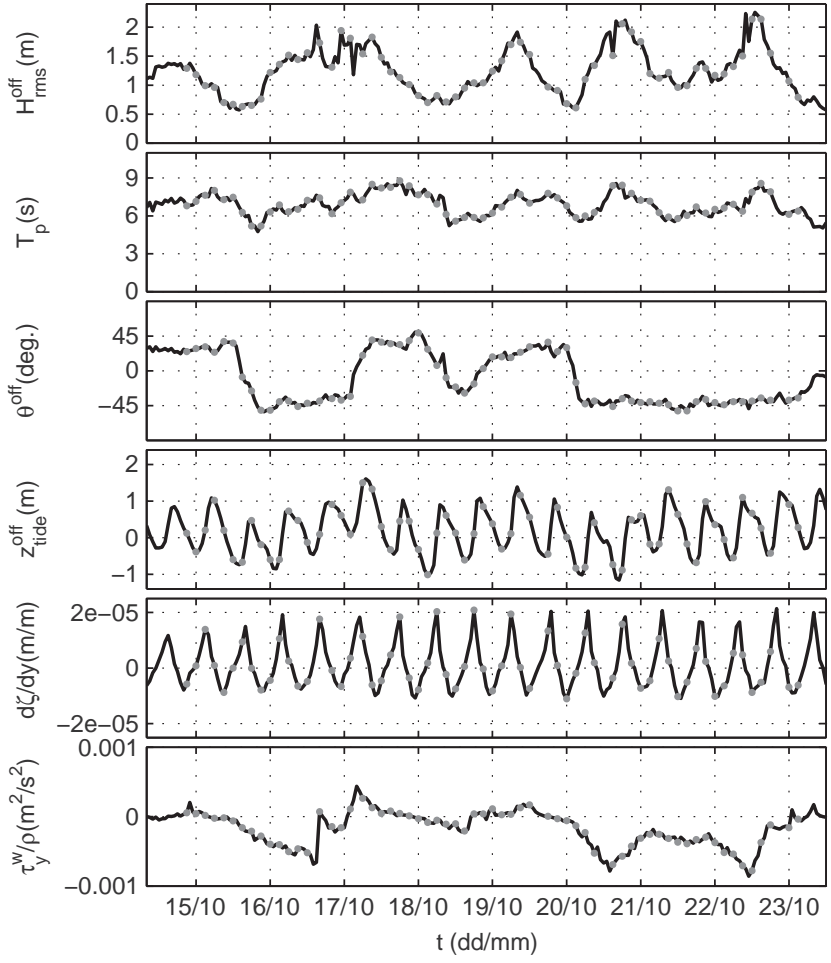

Fig. 5. Offshore conditions measured at Egmond site during October 1998 (Coast3D campaign). The panels show, from top to bottom, the offshore rms wave height, the peak wave period, the offshore angle of wave incidence, the offshore sea surface level, the tide-induced alongshore slope of the sea surface level, and the alongshore component of the wind shear stresses. Solid lines correspond to the measured data and gray dots indicate the input for the model, which was run at selected times (every $3 \mathrm{~h}$ ).

Fig. 8), which had a maximum near or shoreward of the bar crest during most of the time (positions P5 and P6).

\subsection{Model-data comparison and model calibration}

The model was run for a subset of the available hourly data from the 15 to the 23 of October 1998 (see three examples in Fig. 6). A total amount of 63 bursts were (arbitrarily) chosen every $3 \mathrm{~h}$ of observations, so that this subset still contained the large variability of wave, wind and tide conditions of the original data set (gray dots in Fig. 5). Using the default parameter setting (Table 1 ), modeled $H_{\mathrm{rms}}^{o}$ showed a good agreement with observations (Fig. 7), with skill $r^{2} \geq 0.97$ at all sensors (Table 2 ). The corresponding root-mean-square errors, $\varepsilon_{\mathrm{rms}}$, ranged from 0.08 to $0.18 \mathrm{~m}$ at the different sensors, the largest one corresponding to the most offshore located sensor, and the overall $\mathrm{rms}$ error for all sensors was $0.12 \mathrm{~m}$. Since the mean of the observed $H_{\mathrm{rms}}^{o}$ was $0.71 \mathrm{~m}$, the overall relative error of the model (defined as the mean absolute error divided by the mean) was $13 \%$. The slopes of the regression lines between modeled and observed $H_{\mathrm{rms}}^{o}$ (which were forced through the origin) were very close to unity. Good agreement between modeled and observed $V^{0}$ was also obtained (gray dots in Fig. 8), with skills ranging from $r^{2}=0.85$ in the two most offshore located sensors to $r^{2} \geq 0.88$ in the other sensors (Table 2). The corresponding rms errors, $\varepsilon_{\mathrm{rms}}$, ranged from 0.12 to $0.19 \mathrm{~m} / \mathrm{s}$ at the different sensors, with an overall rms error for all sensors of $0.16 \mathrm{~m} / \mathrm{s}$. The overall relative error of the model was of $32 \%$ (the mean of the absolute value of the observed $V^{0}$ being $0.39 \mathrm{~m} / \mathrm{s}$ ). These results are very similar to those obtained by Ruessink et al. (2001) at Egmond site, although they considered a bigger subset of the Coast3D observations.

The model was subsequently run for the 63 bursts using different values of the model parameters $\gamma_{b}, k_{a}, M$ and $\beta_{\text {rol }}$. The default value 

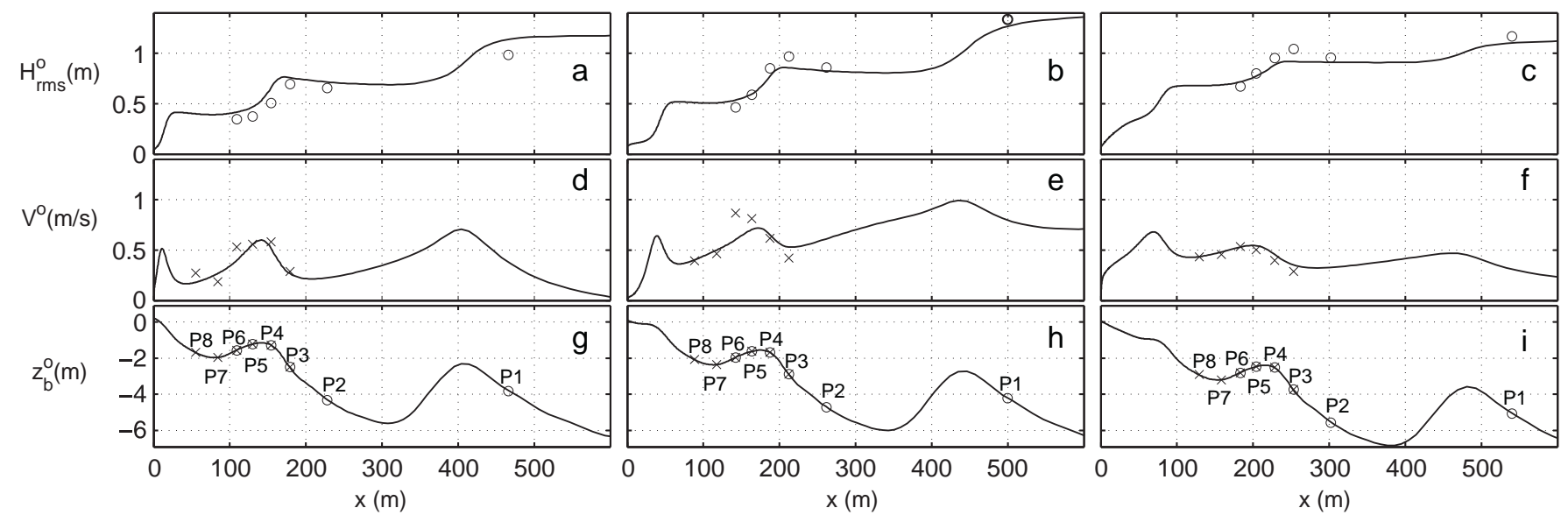

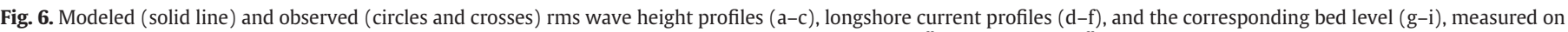

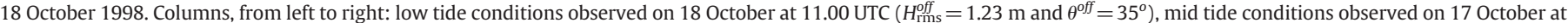

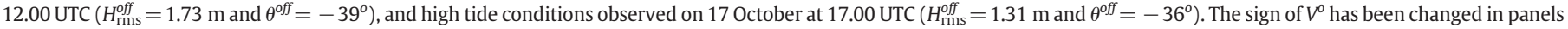
(e) and (f) to facilitate the comparison. The positions of the pressure sensors (circles) and the current meters (crosses) are shown in the bed level panels.

used for the coefficient of saturation ratio, $\gamma_{b}=0.475$, was the one giving the smallest overall rms error of $H_{\mathrm{rms}}^{o}$ (panel (a) of Fig. 9). This value is within the range of values measured in the inner surf zone of USA beaches by Thornton and Guza (1986) and Raubenheimer et al. (1996). We chose to start the calibration by $\gamma_{b}$ because it is the only parameter affecting the rms wave height profile (see Fig. 3).

Afterwards, we calibrated the apparent bed roughness, the default value $k_{a}=0.035 \mathrm{~m}$ being the one giving the smallest overall rms error of $V^{o}$ (panel (b) of Fig. 9). The corresponding $c_{D}$ values ranged from $2 \cdot 10^{-3}$ outside the surf zone to $5 \cdot 10^{-3}$ inside the surf zone, similar to values measured in the field (Feddersen et al., 2003). Ruessink et al. (2001) obtained the best model data agreement for a slightly smaller value of $k_{a}=0.022 \mathrm{~m}$ in Egmond site and $k_{a}=0.0125 \mathrm{~m}$ at Duck

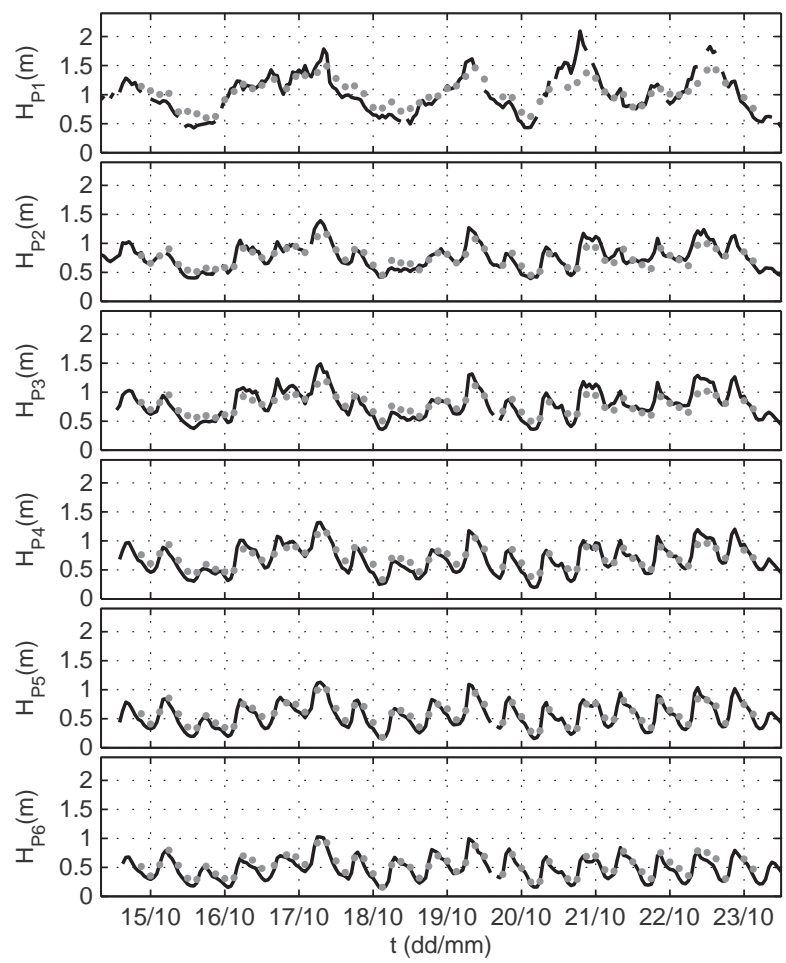

Fig. 7. Field observations at the 6 pressure sensors at Egmond site (solid line) and the corresponding modeled rms wave height (gray dots) from offshore (P1) to onshore (P6) versus time. beach. These differences support the idea that $k_{a}$ should be interpreted as a free model parameter that must be adjusted to get accurate predictions of the longshore current. The sensitivity of the rms error of $V^{o}$ to changing $M$ and $\beta_{\text {rol }}$ was smaller (panels (c) and (d) of Fig. 9). The default values used for these parameters, which were chosen because they were standard values used in the literature, were also in the range of the smaller rms error of $V^{\circ}$.

Finally, the model was run for the 63 bursts using two other model setups and the default parameter values: firstly, the roller dynamics was excluded and secondly the wind and tidal forcing were neglected. In the two cases, the rms errors in the simulated $H^{o}$ profiles remained unchanged. When roller dynamics was not included the rms error of $V^{0}$ worsened by $38 \%$ on average (the rms errors ranging from 0.17 to

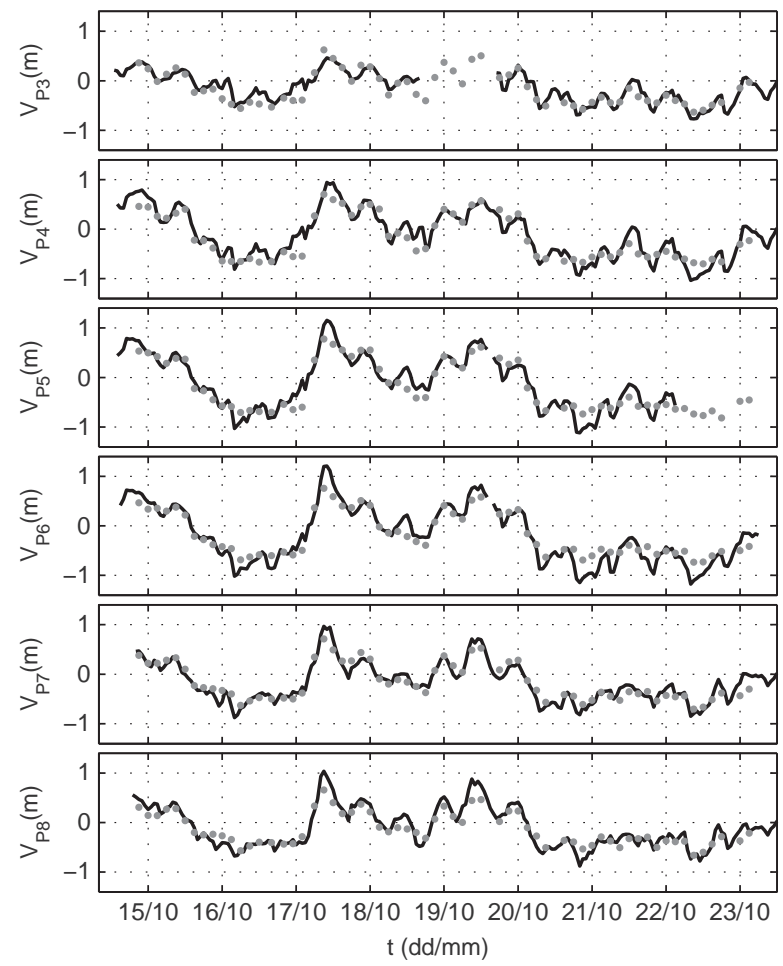

Fig. 8. Field observations at the 6 current meters at Egmond site (solid line) and the corresponding modeled longshore current (gray dots) from offshore (P3) to onshore (P8) versus time. 
Table 2

Statistical results for the rms wave height and longshore current errors using the default model setup and parameter setting.

\begin{tabular}{llllllll}
\hline Data & $\varepsilon_{\text {rms }}(\mathrm{m})$ & $m$ & $r^{2}$ & Data & $\varepsilon_{\text {rms }}(\mathrm{m} / \mathrm{s})$ & $m$ & $r^{2}$ \\
\hline $\mathrm{H}_{\mathrm{P} 1}$ & 0.18 & 1.01 & 0.97 & - & - & - & - \\
$\mathrm{H}_{\mathrm{P} 2}$ & 0.10 & 1.02 & 0.99 & - & - & - & - \\
$\mathrm{H}_{\mathrm{P} 3}$ & 0.11 & 1.02 & 0.98 & $\mathrm{~V}_{\mathrm{P} 3}$ & 0.14 & 0.80 & 0.85 \\
$\mathrm{H}_{\mathrm{P} 4}$ & 0.10 & 0.96 & 0.98 & $\mathrm{~V}_{\mathrm{P} 4}$ & 0.18 & 0.92 & 0.86 \\
$\mathrm{H}_{\mathrm{P} 5}$ & 0.08 & 0.94 & 0.98 & $\mathrm{~V}_{\mathrm{P} 5}$ & 0.18 & 0.98 & 0.89 \\
$\mathrm{H}_{\mathrm{P} 6}$ & 0.09 & 0.90 & 0.98 & $\mathrm{~V}_{\mathrm{P} 6}$ & 0.19 & 1.18 & 0.91 \\
- & - & - & - & $\mathrm{V}_{\mathrm{P} 7}$ & 0.12 & 0.99 & 0.91 \\
- & - & - & - & $\mathrm{V}_{\mathrm{P} 8}$ & 0.15 & 1.15 & 0.88
\end{tabular}

Here $Y_{\text {data }}=m X_{\text {model }}$, we forced a linear relation through the origin.

$0.28 \mathrm{~m} / \mathrm{s}$ in the different sensors, as shown in Table 3). Including surface rollers caused a lag between the dissipation of wave energy and the transfer of momentum to the water column, and thereby created an onshore shift in the location of maximum wave forcing that greatly improved model-data comparison (Reniers et al., 1997; Ruessink et al., 2001). Excluding the roller dynamics in the present study, the longshore current was overpredicted at stations P3-P4 and underpredicted at stations P6-P8 because of the seaward displacement of the modeled longshore current peaks. When wind shear
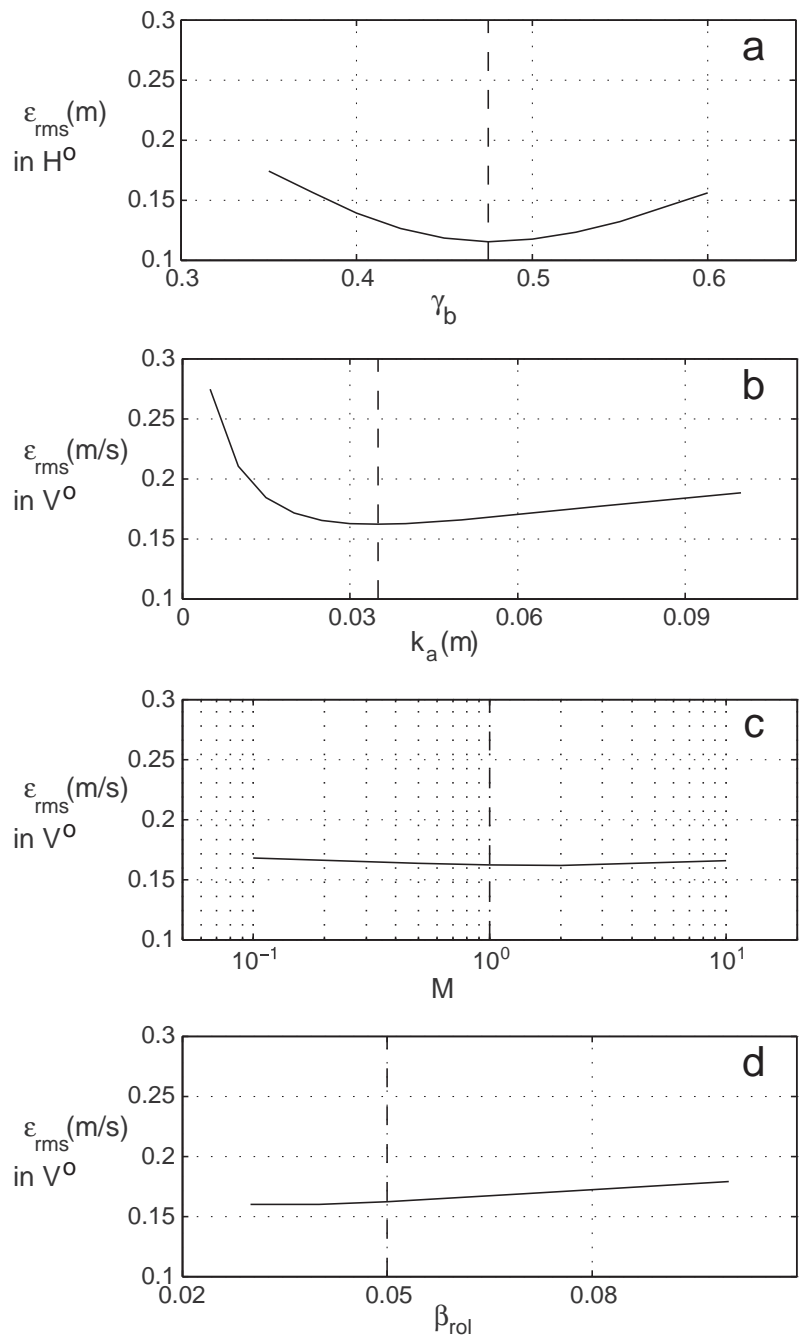

Fig. 9. Sensitivity of the rms errors of modeled rms wave height and longshore current profiles to varying four model parameters. Panel (a) shows the rms error in $H_{\mathrm{rms}}^{o}$ versus $\gamma_{b}$. Panels (b)-(d) show, from top to bottom, the rms error in $V^{o}$ versus $k_{a}$ (b), $M$ (c, where the horizontal axis is exponential) and $\beta_{\text {rol }}(\mathrm{d})$. Vertical dashed lines show the parameter values chosen as default setting.
Table 3

Statistical results for the rms longshore current errors using two other model setups and the default parameter setting.

\begin{tabular}{|c|c|c|c|c|c|c|c|}
\hline \multicolumn{4}{|c|}{ No roller dynamics } & \multicolumn{4}{|c|}{ No wind and tidal forcing } \\
\hline Data & $\varepsilon_{\mathrm{rms}}(\mathrm{m})$ & $m$ & $r^{2}$ & Data & $\varepsilon_{\mathrm{rms}}(\mathrm{m} / \mathrm{s})$ & $m$ & $r^{2}$ \\
\hline $\mathrm{V}_{\mathrm{P} 3}$ & 0.23 & 0.60 & 0.82 & $\mathrm{~V}_{\mathrm{P} 3}$ & 0.16 & 0.95 & 0.74 \\
\hline $\mathrm{V}_{\mathrm{P} 4}$ & 0.25 & 0.72 & 0.85 & $\mathrm{~V}_{\mathrm{P} 4}$ & 0.21 & 1.00 & 0.81 \\
\hline $\mathrm{V}_{\mathrm{P} 5}$ & 0.19 & 1.11 & 0.88 & $\mathrm{~V}_{\mathrm{P} 5}$ & 0.20 & 1.05 & 0.85 \\
\hline $\mathrm{V}_{\mathrm{P} 6}$ & 0.28 & 1.60 & 0.89 & $\mathrm{~V}_{\mathrm{P} 6}$ & 0.25 & 1.30 & 0.86 \\
\hline$V_{\mathrm{P} 7}$ & 0.17 & 1.40 & 0.91 & $\mathrm{~V}_{\mathrm{P} 7}$ & 0.19 & 1.12 & 0.79 \\
\hline $\mathrm{V}_{\mathrm{P} 8}$ & 0.20 & 1.34 & 0.84 & $\mathrm{~V}_{\mathrm{P} 8}$ & 0.21 & 1.41 & 0.83 \\
\hline
\end{tabular}

Here $Y_{\text {data }}=m X_{\text {model }}$, we forced a linear relation through the origin.

stresses and tide-induced sea level slopes were neglected, the rms error of $V^{\circ}$ became worse by $28 \%$ on average, ranging from 0.16 to $0.25 \mathrm{~m} / \mathrm{s}$ in the different sensors (Table 3 ). The rms errors were largest in the sensors P4-P6 located in the trough of the inner bar, the region where forcing due to wave radiation stresses was smallest. This result is in line with those of Feddersen et al. (1998); Ruessink et al. (2001), who showed that the forcing by wind shear stresses and alongshore sea level slopes due to tides can be up to $20 \%$ of the wave forcing over the bar-trough region (their effect being strongest in the regions with smallest wave forcing).

\section{Modeling the initial development of nearshore sandbars}

\subsection{Model results at Noordwijk site}

After the validation of the basic reference state, the model was applied to the specific wave and bathymetric conditions measured at Noordwijk site (the Netherlands) during the up-current finger bar event that occurred in August-September 2002 (Fig. 1). The default

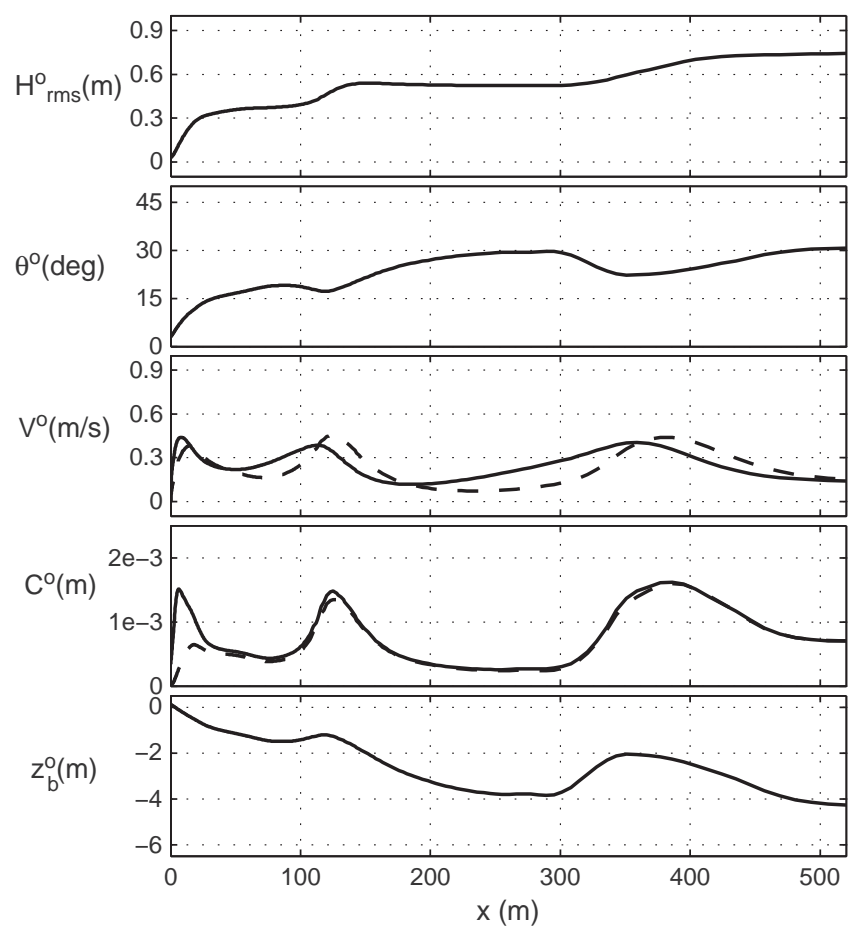

Fig. 10. Result for the reference state at Noordwijk site using the default parameter setting. The panels show, from top to bottom, the cross-shore profiles of the rms wave height, the angle of wave incidence with respect to shore-normal, the longshore current (default setup in solid line, no roller setup in dashed line), the depth-integrated suspended sediment concentration (default setup in solid line, no roller setup in dashed line) and the bed level. The bathymetry was measured at Noordwijk site, the Netherlands, on 3 October 2002 for a tidal level of $-0.38 \mathrm{~m}$. 
model setup and parameter setting (Table 1) were used because they were those which best resembled Egmond wave height and longshore current data (remember that no $H_{\mathrm{rms}}^{o}$ and $V^{o}$ measurements were available at Noordwijk site). We considered that the model calibration done at Egmond site would be still valid at Noordwijk site because the offshore conditions, the sediment properties and the bathymetry are very similar in these beaches. Note that they belong to the same long uninterrupted Dutch coast, separated by only $45 \mathrm{~km}$ alongshore. The profile at $y=-500 \mathrm{~m}$ of the bathymetric survey made at Noordwijk beach on 3 October 2002 was used as reference profile (this was the transect closest to the up-current finger bars observed in AugustSeptember 2002, see Fig. 1). The offshore wave conditions of the default parameter setting were within the range of values measured at Noordwijk buoy during that transverse bar patch event (Ribas and Kroon, 2007). Two values for the parameter $n_{\text {bor }}$ were used to calculate the depth-integrated suspended sediment concentration $C$ (Eqs. (17) and (18)): the default one, $n_{\text {bor }}=50$, and also $n_{\text {bor }}=0$, which was equivalent to using the original Soulsby and van Rijn formulation (no roller-induced stirring). The model was also run neglecting the roller dynamics, in which case the roller-induced stirring is also equal to 0 , as shown in Eq. (19).

Fig. 10 shows the result for the basic reference state at Noordwijk site, including the profile of $C^{o}$. In the $V^{o}$ and $C^{o}$ panels, the solutions for both the default setup and the setup without rollers are shown. When neglecting the roller dynamics, the profile of $V^{0}$ showed offshore-shifted peaks, as expected. The two profiles of $C^{\circ}$ diverged in the inner surf zone (compare the solid line with the dashed line in the first 30 cross-shore meters), mostly due to the influence of the roller-induced extra stirring.
The $C^{0}$ profile obtained when including the rollers but using $n_{\text {bor }}=0$ (not shown) was very similar to the one obtained neglecting the roller dynamics (dashed line). The profiles of the rest of the quantities shown in Fig. 10 were equal in the three model configurations.

When the linear stability analysis (Section 2.3) was performed using the default setup (i.e. with rollers and $n_{\text {bor }}=50$ ) two distinct lines appeared in the growth rate curve (see panel (a) of Fig. 11). The Fastest Growing Solution (FGS from now on) was the one with $\kappa_{M}=$ $0.120 \mathrm{~m}^{-1}$, which corresponded to a wavelength $\lambda_{M}=52 \mathrm{~m}$, an efolding growth time $\tau_{M}=36 \mathrm{~h}$ and a migration rate $c_{M}=1.4 \mathrm{~m} / \mathrm{h}$ (see the panel (b) of Fig. 11). Panel (c) in Fig. 11 displays the shape of the topographic perturbation corresponding to this FGS. The solution consisted of a patch of up-current oriented bars, whose crests deviated some $45^{\circ}$ from the shore-normal, with current perturbations deflecting offshore over their crests. In order to visualize the final shape of the bottom, the reference profile, $z_{b}^{o}$, should be added. The same applies to the flow: the longshore current $V^{0}$ should be added to the perturbations of the velocity to obtain the total flow. A secondary mode for smaller wavenumbers was also obtained in the growth rate curve, the corresponding local maximum having a wavelength $\lambda_{M}=$ $630 \mathrm{~m}$, an e-folding growth time $\tau_{M}=56 \mathrm{~h}$ and a migration rate $c_{M}=$ $4.0 \mathrm{~m} / \mathrm{h}$. The topographic pattern corresponding to this secondary mode was a crescentic bar, as is shown in panel (d) of Fig. 11.

The influence of the rollers into nearshore bar formation was tested by applying the model in the two other setups and comparing the result with the default case one. When the model was applied with $n_{\text {bor }}=0$, no up-current bars were obtained. The only perturbation with positive growth rates corresponded to a crescentic bar

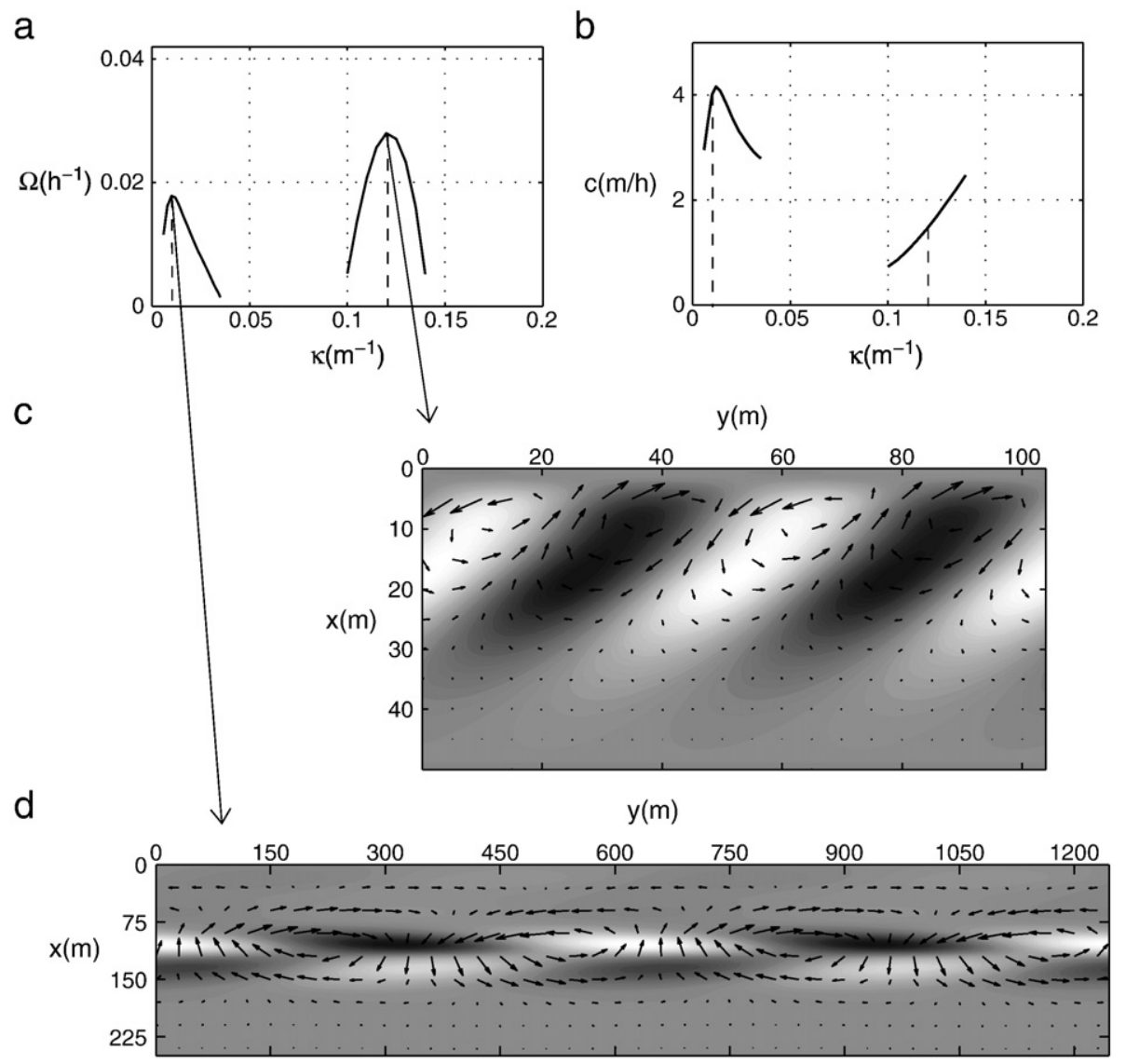

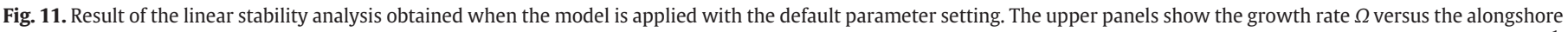

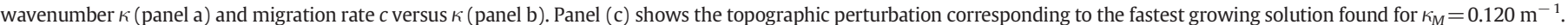

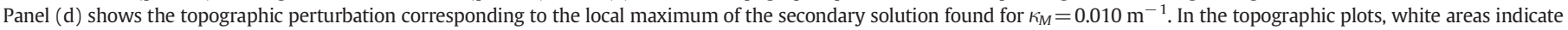

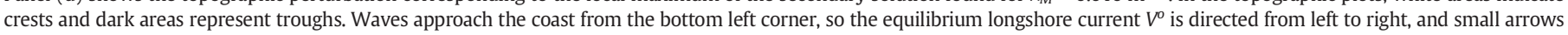
indicate the current perturbations. 
Table 4

Comparison between the results of the Linear Stability Analysis using three different model setups.

\begin{tabular}{|c|c|c|c|c|c|}
\hline \multicolumn{2}{|c|}{ Default setup (rollers and $n_{\text {bor }}=50$ ) } & \multicolumn{2}{|c|}{ With rollers but $n_{\text {bor }}=0$} & \multicolumn{2}{|l|}{ No rollers } \\
\hline Up-current bars & Crescentic bar & Up-current bars & Crescentic bar & Up-current bars & Crescentic bar \\
\hline$\lambda_{M}=52 \mathrm{~m}$ & $\lambda_{M}=630 \mathrm{~m}$ & No growth & $\lambda_{M}=630 \mathrm{~m}$ & No growth & $\lambda_{M}=790 \mathrm{~m}$ \\
\hline$\tau_{M}=36 \mathrm{~h}$ & $\tau_{M}=56 \mathrm{~h}$ & $(\Omega<0)$ & $\tau_{M}=68 \mathrm{~h}$ & $(\Omega \sim 0)$ & $\tau_{M}=72 \mathrm{~h}$ \\
\hline$c_{M}=1.4 \mathrm{~m} / \mathrm{h}$ & $c_{M}=4.0 \mathrm{~m} / \mathrm{h}$ & & $c_{M}=3.6 \mathrm{~m} / \mathrm{h}$ & & $c_{M}=6.0 \mathrm{~m} / \mathrm{h}$ \\
\hline
\end{tabular}

pattern with characteristics similar to the one obtained with the default parameter setting (Table 4). When the model was applied neglecting the roller dynamics, the obtained FGS also corresponded to a crescentic bar pattern, with a wavelength and a migration rate about $30 \%$ larger than those of the default case.

\subsection{Discussion and comparison with Noordwijk observations}

The modeled wavelengths and shapes of the up-current oriented bars obtained for the default model setup were in good agreement with the observed values. Ribas and Kroon (2007) measured the event-averaged wavelength of the up-current bar event occurring at Noordwijk in August-September 2002, giving a value of $\lambda=46 \mathrm{~m}$. The angle of deviation of the bar crests from the shore-normal was smaller in the observations, with values of some $30^{\circ}$. The modeled migration rate was some 1.5 times larger than the maximum rate detected in the field $(0.9 \mathrm{~m} / \mathrm{h})$ and one order of magnitude larger than the eventaveraged observed rate $(0.13 \mathrm{~m} / \mathrm{h})$. Measuring the growth rate of the bars at the beach was not possible due to the nature of the detection technique (video imaging). However, it could be established that bar emerged in time scales of the order of 1 day, well within the modeled time for growth.

The similarities between the model results and the Noordwijk upcurrent finger bars indicate that the bed-flow interaction, described in Section 1, is a viable explanation for their formation. Fig. 12 shows the cross-shore profile of the depth-averaged suspended sediment concentration, $C_{d a}=C / D$, for the three model configurations. An offshore decreasing cross-shore distribution of $C_{d a}$, crucial to obtain up-current bar formation, is only obtained by including the turbulence resuspension linked to roller propagation (compare the solid line with the other two lines in the bottom panel). Thereby, the formation of upcurrent oriented bars, like those observed at Noordwijk beach, can only be modeled when including not only the roller dynamics but also the extra sediment stirring due to the turbulence created by the roller propagation. In order to validate this physical mechanism and the corresponding sediment transport formulation (Eqs. (16)-(19)), the cross-shore profile of $C_{d a}$ should be measured in beaches where upcurrent oriented finger bars develop. It can be estimated that including

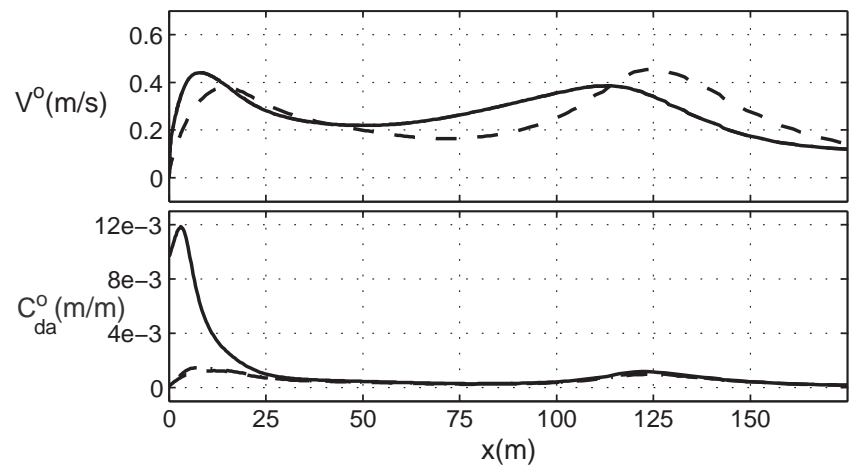

Fig. 12. Cross-shore profile of the longshore current (top) and the depth-averaged concentration of suspended sediment (bottom) for the default setup with rollers and $n_{\text {bor }}=50$ (solid line), for the setup with rollers but $n_{\text {bor }}=0$ (dot-dashed line, located below the solid line in the top panel) and for the no roller setup (dashed line, located close to the dot-dashed line in the bottom panel). the sediment resuspension created by the roller-induced turbulence increases by some $10 \%$ the total longshore sediment transport, $Q^{\circ}$. The latter quantity is obtained by integrating in the cross-shore direction (from $x=0$ to $x=750 \mathrm{~m}$ ) the basic state profile of the alongshore component of the sediment transport, $q_{2}^{o}=C V^{\circ}$ (Eq.(16)). For instance, $Q^{o}$ increases from $0.12 \mathrm{~m}^{3} / \mathrm{s}$ to $0.13 \mathrm{~m}^{3} / \mathrm{s}$ if $n_{\text {bor }}$ is changed from 0 to 50 (in the default parameter setting).

The shape of the crescentic bar modeled with the default model setup was also in good agreement with observations, but the modeled migration rate was 1.5 times larger than the maximum values reported by van Enckevort et al. (2004) at Noordwijk site. The crescentic bars observed in that site during August-September 2002 showed wavelengths of some $500 \mathrm{~m}$ and alongshore migration rates up to $2.5 \mathrm{~m} / \mathrm{h}$. The solutions modeled for the two values of $n_{\text {bor }}$ were very similar (Table 4), meaning that the roller-induced resuspension does not play an important role in crescentic bar formation. However, neglecting roller dynamics (which is done in the majority of studies of crescentic bar formation) gave crescentic bars with too large wavelengths and migration rates. This seems to be linked to the shift of the peak of the longshore current above the inner bar (compare the solid and dashed lines in the $V^{\circ}$ panel of Fig. 12). The longshore current profile obtained including the roller dynamics, with a wider peak located in the shoreward side of the inner bar, was linked to crescentic bars more similar to the ones observed by van Enckevort et al. (2004).

For all the model configurations, the characteristic time for growth of the crescentic bars was rather large using the default parameter setting (Table 4). The bed-surf interaction, which explains the formation of crescentic bars, predicts faster growing solutions for less oblique waves (Calvete et al., 2005). The model was thereby run for $\theta=25^{\circ}$ instead of $\theta=50^{\circ}$ (and the three model setups), the corresponding results being shown in Table 5 . The modeled growth times of the crescentic bars decreased by $50 \%$ and the wavelengths and migration rates were again more realistic when including rollers. Formation of up-current bars was not obtained for this angle of wave incidence, in agreement with observations (Ribas and Kroon, 2007). The bed-flow interaction, which explains the formation of up-current bars, only dominates for large values of $\theta^{\text {off }}$ (Ribas et al., 2003).

\section{Conclusions}

The rollers play an essential role in the dynamics of longshore currents. They cause an onshore shift in the location of the maximum wave forcing and hence of the peak of the longshore currents. Only when rollers are included, the modeled cross-shore distribution of the longshore current agrees well with measured data at Egmond site, the Netherlands. Including the wind shear stresses and the tide-induced sea level slope also improves the model skill. After calibrating the

Table 5

Comparison between the results of the Linear Stability Analysis using the three different model setups and for $\theta=25^{\circ}$ (instead of $\theta=50^{\circ}$ ).

\begin{tabular}{|c|c|c|}
\hline Default setup & Rollers but $n_{\text {bor }}=0$ & No rollers \\
\hline Crescentic bar & Crescentic bar & Crescentic bar \\
\hline$\lambda_{M}=450 \mathrm{~m}$ & $\lambda_{M}=450 \mathrm{~m}$ & $\lambda_{M}=630 \mathrm{~m}$ \\
\hline$\tau_{M}=21 \mathrm{~h}$ & $\tau_{M}=25 \mathrm{~h}$ & $\tau_{M}=21 \mathrm{~h}$ \\
\hline$c_{M}=4.7 \mathrm{~m} / \mathrm{h}$ & $c_{M}=4.1 \mathrm{~m} / \mathrm{h}$ & $c_{M}=5.8 \mathrm{~m} / \mathrm{h}$ \\
\hline
\end{tabular}


values of the coefficient of saturation ratio and the apparent bed roughness, the model yields root-mean-square (rms) wave height profiles with an overall rms error of $0.12 \mathrm{~m}$ and longshore current profiles with an overall rms error of $0.16 \mathrm{~m} / \mathrm{s}$, similar to previous studies.

The crescentic bars modeled when including the roller dynamics are more similar to the observed ones. The modeled wavelength (of the order of $500 \mathrm{~m}$ ) and migration rate (of some $4 \mathrm{~m} / \mathrm{h}$ ) are in qualitative agreement with those of crescentic bars observed at Noordwijk site, the Netherlands. The improvement seems to be due to the onshore shift of the longshore current peak over the inner bar. The longshore current profiles obtained when neglecting the roller dynamics (with a narrow peak located in the seaward side of the inner bar) are linked to the formation of crescentic bars with too large wavelengths and migration rates.

The rollers also create turbulent bores that lead to significant sediment resuspension in the inner surf zone. This results in a crossshore distribution of the depth-averaged suspended sediment concentration that explains the formation of up-current oriented finger bars at Noordwijk site. Indeed, realistic positive feedback leading to formation of bars like those observed only occurs if the sediment resuspension due to roller-induced turbulence is included in the model. In that case, the depth-averaged suspended sediment concentration decreases seaward across most of the inner surf zone. This, in combination with an offshore-directed flow over the bars, leads to accumulation of sediment in the crest areas. The up-current oriented shape, the wavelength (of some $50 \mathrm{~m}$ ) and the growth rate (of the order of one day) of the modeled bars are in good agreement with those of observed transverse finger bars at Noordwijk. However, modeled migration speeds (of the order of $1 \mathrm{~m} / \mathrm{h}$ ) are higher than those measured in the field. Field measurements of the depthaveraged suspended sediment concentration in beaches with upcurrent oriented finger bars are needed to validate this mechanism.

\section{Acknowledgments}

Funding from the Spanish research project 'Morfodinámica de playas: predicciones en las grandes escalas espacio-temporales' (contract CTM2006-08875/MAR) is acknowledged. Data collected near Egmond aan Zee (the Netherlands) during the Coast3D experiment, together with a lot of explanations, were kindly provided by Dr. Gerben Ruessink.

\section{References}

Apotsos, A., Raubenheimer, B., Elgar, S., Guza, R.T., Smith, J.A., 2007. Effects of wave rollers and bottom stress on wave setup. J. Geophys. Res. 112 (C02003). doi:10.1029/2006JC003549.

Butt, T., Russel, P., Puleo, J., Miles, J., Masselink, G., 2004. The influence of bore turbulence on sediment transport in the swash and inner surf zones. Cont. Shelf Res. 24, 757-771.
Caballeria, M., Coco, G., Falqués, A., Huntley, D.A., 2002. Self-organization mechanisms for the formation of nearshore crescentic and transverse sand bars. J. Fluid Mech. $465,379-410$.

Calvete, D., Dodd, N., Falqués, A., van Leeuwen, S.M., 2005. Morphological development of rip channel systems: normal and near normal wave incidence. J. Geophys. Res. 110 (C10006). doi:10.1029/2004JC002803.

Damgaard, J., Dodd, N., Hall, L., Chesher, T., 2002. Morphodynamic modelling of rip channel growth. Coastal Eng. 45, 199-221.

Deigaard, R., Drønen, N., Fredsoe, J., Jensen, J.H., Jørgensen, M.P., 1999. A morphological stability analysis for a long straight barred coast. Coastal Eng. 36 (3), 171-195.

Dodd, N., Blondeaux, P., Calvete, D., de Swart, H.E., Falqués, A., Hulscher, S.J.M.H., Różyński, G., Vittori, G., 2003. The use of stability methods in understanding the morphodynamical behavior of coastal systems. J. Coast. Res. 19 (4), 849-865.

Falqués, A., Coco, G., Huntley, D.A., 2000. A mechanism for the generation of wave-driven rhythmic patterns in the surf zone. J. Geophys. Res. 105 (C10), 24071-24088.

Feddersen, F., Guza, R.T., Elgar, S., Herbers, T.H.C., 1998. Alongshore momentum balances in the nearshore. J. Geophys. Res. 103 (C8), 15667-15676.

Feddersen, F., Guza, R.T., Elgar, S., Herbers, T.H.C., 2000. Velocity moments in alongshore bottom stress parameterizations. J. Geophys. Res. 105 (C4), 8673-8686.

Feddersen, F., Gallagher, E.L., Guza, R.T., Elgar, S., 2003. The drag coefficient, bottom roughness, and wave-breaking in the nearshore. Coastal Eng. 48, 189-195.

Garnier, R., Calvete, D., Falqués, A., Caballeria, M., 2006. Generation and nonlinear evolution of shore-oblique/transverse sand bars. J. Fluid Mech. 567, 327-360.

Garnier, R., Calvete, D., Falqués, A., Dodd, N., 2008. Modelling the formation and the long-term behavior of rip channel systems from the deformation of a longshore bar. J. Geophys. Res. 113 (C07053). doi:10.1029/2007JC004632.

Klein, M.D., Schuttelaars, H.M., 2005. Morphodynamic instabilities of planar beaches: sensitivity to parameter values and process formulations. J. Geophys. Res. 110 (F04S18). doi:10.1029/2004JF000213.

Konicki, K.M., Holman, R.A., 2000. The statistics and kinematics of transverse bars on an open coast. Mar. Geol. 169, 69-101.

Lippmann, T.C., Brookins, A.H., Thornton, E.B., 1996. Wave energy transformation on natural profiles. Coastal Eng. 27, 1-20.

Raubenheimer, B., Guza, R.T., Elgar, S., 1996. Wave transformation across the inner surf zone. J. Geophys. Res. 101 (C10), 25589-25597.

Reniers, A.J.H.M., Battjes, J.A., Falqués, A., Huntley, D.A., 1997. A laboratory study on the shear instability of longshore currents. J. Geophys. Res. 102 (C4), 8597-8609.

Reniers, A.J.H.M., Roelvink, J.A., Thornton, E.B., 2004. Morphodynamic modeling of an embayed beach under wave group forcing. J. Geophys. Res. 109 (C01030). doi:10.1029/2002JC001586.

Ribas, F., Kroon, A., 2007. Characteristics and dynamics of surfzone transverse finger bars. J. Geophys. Res. 112 (F03028). doi:10.1029/2006JF000685.

Ribas, F., Falqués, A., Montoto, A., 2003. Nearshore oblique sand bars. J. Geophys. Res. 108 (C43119). doi:10.1029/2001JC000985.

Roelvink, J.A., Stive, M.J.F., 1989. Bar-generating cross-shore flow mechanisms on a beach. J. Geophys. Res. 94 (C4), 4785-4800.

Ruessink, B.G., Miles, J.R., Feddersen, F., Guza, R.T., Elgar, S., 2001. Modeling the alongshore current on barred beaches. J. Geophys. Res. 106 (C10), 22451-22463.

Short, A.D., 1999. Handbook of Beach and Shoreface Morphodynamics. Wiley, Chichester.

Soulsby, R.L., 1997. Dynamics of Marine Sands. Thomas Telford, London, U.K

Svendsen, I., 1984. Mass flux and undertow in the surf zone. Coastal Eng. 8, 347-365.

Thornton, B., Guza, R.T., 1983. Transformation of wave height distribution. J. Geophys. Res. 88 (10), 5925-5938.

Thornton, B., Guza, R.T., 1986. Surf zone longshore currents and random waves: field data and models. J. Phys. Oceanogr. 16, 1165-1178.

van Enckevort, I.M. ., Ruessink, B.G., Coco, G., Suzuki, K., Turner, I.L., Plant, N.G., Holman, R.A., 2004. Observations of nearshore crescentic sandbars. J. Geophys. Res. 109 (C06028). doi:10.1029/2003JC002214.

van Leeuwen, S.M., Dodd, N., Calvete, D., Falqués, A., 2006. Physics of nearshore bed pattern formation under regular or random waves. J. Geophys. Res. 111 (F01023). doi:10.1029/2005JF000360.

Voulgaris, G., Collins, M.B., 2000. Sediment resuspension on beaches: response to breaking waves. Mar. Geol. 167, 167-187.

Wright, L.D., Short, A.D., 1984. Morphodynamic variability of surf zones and beaches: a synthesis. Mar. Geol. 56, 93-118. 